\title{
Oil and macroeconomic (in)stability
}

\section{CAMA Working Paper 79/2017 December 2017}

\section{Hilde C. Bjørnland}

Centre for Applied Macro- and Petroleum analysis (CAMP) BI Norwegian Business School Norges Bank and

Centre for Applied Macroeconomic Analysis, ANU

\section{Vegard H. Larsen}

Centre for Applied Macro- and Petroleum analysis (CAMP) BI Norwegian Business School

Norges Bank

\section{Junior Maih}

Centre for Applied Macro- and Petroleum analysis (CAMP) BI Norwegian Business School

Norges Bank

\section{Abstract}

We analyze the role of oil price volatility in reducing U.S. macroeconomic instability. Using a Markov Switching Rational Expectation New-Keynesian model we revisit the timing of the Great Moderation and the sources of changes in the volatility of macroeconomic variables. We find that smaller or fewer oil price shocks did not play a major role in explaining the Great Moderation. Instead oil price shocks are recurrent sources of economic fluctuations. The most important factor reducing overall variability is a decline in the volatility of structural macroeconomic shocks. A change to a more responsive (hawkish) monetary policy regime also played a role. 


\title{
Keywords
}

Oil price, Great Moderation, New-Keynesian model, Markov Switching

\author{
JEL Classification
}

C11, E32, E42 Q43

Address for correspondence:

(E) cama.admin@anu.edu.au

ISSN 2206-0332

The Centre for Applied Macroeconomic Analysis in the Crawford School of Public Policy has been established to build strong links between professional macroeconomists. It provides a forum for quality macroeconomic research and discussion of policy issues between academia, government and the private sector.

The Crawford School of Public Policy is the Australian National University's public policy school, serving and influencing Australia, Asia and the Pacific through advanced policy research, graduate and executive education, and policy impact. 


\title{
Oil and macroeconomic (in)stability
}

\author{
Hilde C. Bjørnland, Vegard H. Larsen and Junior Maih*
}

November 28, 2017

\begin{abstract}
We analyze the role of oil price volatility in reducing U.S. macroeconomic instability. Using a Markov Switching Rational Expectation New-Keynesian model we revisit the timing of the Great Moderation and the sources of changes in the volatility of macroeconomic variables. We find that smaller or fewer oil price shocks did not play a major role in explaining the Great Moderation. Instead oil price shocks are recurrent sources of economic fluctuations. The most important factor reducing overall variability is a decline in the volatility of structural macroeconomic shocks. A change to a more responsive (hawkish) monetary policy regime also played a role.
\end{abstract}

JEL: C11, E32, E42 Q43

Keywords: Oil price, Great Moderation, New-Keynesian model, Markov Switching

*Hilde C. Bjørnland: Centre for Applied Macro- and Petroleum analysis (CAMP) BI Norwegian Business School), Centre for Applied Macroeconomic Analysis (CAMA) ANU and Norges Bank. (email: hilde.c.bjornland@bi.no). Vegard Larsen: CAMP BI Norwegian Business School and Norges Bank (email: vegard.h.larsen@bi.no). Junior Maih: Norges Bank and CAMP BI Norwegian Business School (email: junior.maih@norges-bank.no). The authors would like to thank three anonymous referees, Drago Bergholt, Marcelle Chauvet, Gernot Doppelhofer, Ana Maria Herrera, Haroon Mumtaz, Gisle Natvik, Tommy Sveen and Leif Anders Thorsrud, as well as seminar and conference participants at Indiana University, Melbourne University, the Reserve Bank of New Zealand, the CFE 2014 conference in Pisa, the SNDE 2015 Symposium in Oslo and the 2015 World Congress of the Econometric Society in Montreal for valuable comments. This paper is part of the research activities at the Centre for Applied Macro and Petroleum economics (CAMP) at the BI Norwegian Business School. The views expressed are those of the authors and do not necessarily reflect those of Norges Bank. The usual disclaimers apply. 


\section{Introduction}

Has declining oil price volatility contributed to a more stable macroeconomic environment since the mid-1980s, or do high and volatile oil prices still make a material contribution to recessions? The views are diverse. According to Hamilton (2009), the run-up of oil prices in 2007-08 had very similar contractionary effects on the U.S. economy as earlier oil price shocks (such as in the 1970s), and this period should therefore be added to the list of recessions to which oil prices appear to have made a material contribution. ${ }^{1}$ Others argue for a reduced role for oil as a cause of recessions in the last decade(s). For instance, Nakov and Pescatori (2010) and Blanchard and Gali (2008) analyze the U.S. prior to and post 1984, and find that less volatile oil sector shocks (i.e., good luck) can explain a significant part of the reduction in the volatility of inflation and GDP growth post 1984, a period commonly referred to as the Great Moderation in the economic literature. In addition, better (or more effective) monetary policy (i.e., good policy) has also played an important role, in particular in reducing the volatility of inflation.

Common to studies such as Nakov and Pescatori (2010) and Blanchard and Gali (2008) is the fact that they analyze the volatility of oil price shocks and the effectiveness of monetary policy by comparing macroeconomic performance before and after a given break point in time (typically 1984). There are several reasons why analyzing the relationship between oil price volatility and macroeconomic volatility in a split sample framework such as this may give misleading results. First, while the persistent decline in macroeconomic volatility since the mid 1980s is well documented for many variables, see among others Kim and Nelson (1999a), McConnell and Perez-Quiros (2000), Stock and Watson (2003) and Canova, Gambetti and Pappa (2007), it is not clear whether there has been a systematic reduction in oil price volatility that coincides with this Great Moderation. Instead, large fluctuations in the oil price seem to be a recurrent feature of the economic environment, but with a sharp increase in volatility in the first quarter of 1974 standing out, see Figure 1. ${ }^{2}$ Second, policy may also have changed multiple times in the last decades. For instance Bikbov and Chernov (2013) show that although policymakers were less concerned with the stabilization of inflation in the 1970s than from the mid 1980s, the stabilization of

\footnotetext{
${ }^{1}$ Since the seminal paper by Hamilton (1983), a large body of literature has appeared documenting a significant negative relationship between (exogenous) oil price increases and economic activity in a number of different countries (see, e.g., Burbidge and Harrison (1984), Gisser and Goodwin (1986), Hamilton (1996, 2003, 2009) and Bjørnland (2000) among many others). Higher energy prices typically lead to an increase in production costs and inflation, thereby reducing overall demand, output and trade in the economy.

${ }^{2}$ In 1974, OPEC announced an embargo on oil exports to some countries supporting Israel during the attack on Israel led by Syria and Egypt. This led to a fall in oil production and almost a doubling in oil prices in the first quarter of 1974.
} 


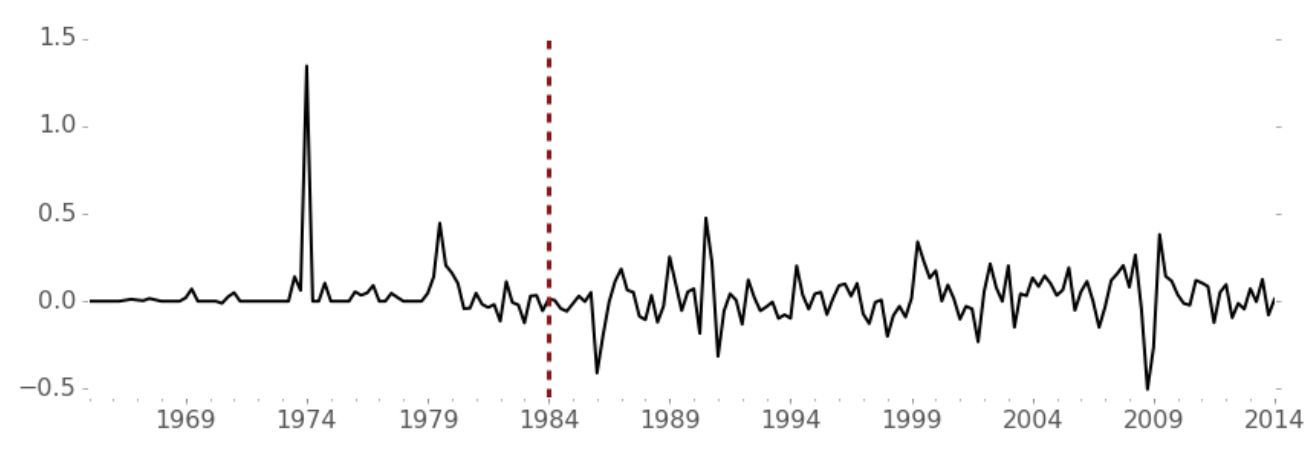

Figure 1: Percentage change in the real price of oil (WTI)

Note: The figure shows the quarterly percentage change in the real price of oil. The vertical red line is plotted for 1984Q1.

inflation also prompted less concern during several brief periods in the 1990s and 2000s. And when agents are aware of the possibility of such regime changes, their beliefs will matter for the law of motion underlying the economy, see e.g., Bianchi (2013).

Instead of splitting the sample, this paper analyzes the role of oil price volatility in reducing macroeconomic instability using a Markov Switching Rational Expectation NewKeynesian model. The model accommodates regime-switching behavior in shocks to oil prices, macro variables as well as in monetary policy responses. With the structural model we revisit the timing of the Great Moderation (if any) and the sources of changes in the volatility of macroeconomic variables. In so doing, we make use of the Newton algorithm of Maih (2014), which is similar in spirit but distinct from that of Farmer, Waggoner and Zha (2011). As demonstrated in Maih (2014), this algorithm is more general, more efficient and more robust than that of Farmer, Waggoner and Zha (2011). The model is estimated using Bayesian techniques accommodating different regimes or states within one model. We estimate a model where the parameters may switch in combination, allowing for a simultaneous inference on both the policy parameters and the stochastic volatilities.

There are now several papers that analyze the so called good policy versus good luck hypothesis using a regime switching framework, see e.g. Stock and Watson (2003), Sims and Zha (2006), Liu, Waggoner and Zha (2011), Bianchi (2013) and Baele et al. (2015). While none of these papers analyzes the effect of oil price volatility directly, oil price shocks are often suggested candidates for the heightened volatility of the 1970s, see in particular Sims and Zha (2006). We contribute to this literature by examining the role of oil price volatility explicitly, allowing also for regime switching in the volatility of other demand and supply shocks and in policy responses using the MSRE model.

A concern with the New-Keynesian model framework used by Blanchard and Gali (2008) is that it may be too stylized to be viewed as structural for the purposes of assessing the role of oil versus other shocks as driving forces for the U.S. economy. To 
deal with this we reformulate the model in terms of a medium scale Dynamic Stochastic General Equilibrium (DSGE) model with nominal rigidities in the spirit of Christiano, Eichenbaum and Evans (2005). This allows us to expand the model framework, so that we can have direct data on variables such as capital, wages and consumption, which is key to assessing the strength of the oil channel in a well-specified structural framework. This also allows for a comparison of results with studies that allow for (more general) regime switches in the macroeconomic dynamics and monetary policy responses using the Markov Switching DSGE (MSDSGE) framework, see in particular Liu, Waggoner and Zha (2011) and Bianchi (2013) for earlier contributions.

Finally, and in contrast to Blanchard and Gali (2008) and Nakov and Pescatori (2010), we allow oil prices to also respond to global activity. This follows Kilian (2009), who suggests there is a "reverse causality" from the macroeconomy to oil prices. In particular, he finds that if the increase in the oil price is driven by an increased demand for oil associated with fluctuations in global activity and not disruptions of supply capacity, global economic activity may be less negatively affected. ${ }^{3}$ Hence, when examining the consequences of an oil price increase on the U.S. economy, it seems important to allow the oil price to also respond to global activity.

We have three major findings. First, our results support regime switching behavior in monetary policy, U.S. macroeconomic shock volatility and oil price shock volatility. In particular, to fully understand the role of oil in the macroeconomy, it is important to separate between periods of low and high oil price volatility. Constant parameter models will underestimate the role of oil.

Second, we find no break in oil price volatility to coincide with the Great Moderation. Instead, we find several short periods of heightened oil price volatility throughout the whole sample, many of them preceding the dated NBER recessions. If anything, the post1984 period has had more episodes of high oil price volatility than the pre-1984 period. According to our results, then, we cannot argue that a decline in oil price volatility was a factor in the reduced volatility of other U.S. macroeconomic variables post 1984. Instead, we confirm the relevance of oil as a recurrent source of macroeconomic fluctuations, not only in the past but also in recent times. This is a new finding in the literature.

Third, the most important factor reducing macroeconomic variability is a decline in the volatility of structural macroeconomic shocks. The break date is estimated to occur in 1984/1985. That is not to say there were no surges in volatility after this time. However,

\footnotetext{
${ }^{3}$ Corroborating results are shown in e.g. Lippi and Nobili (2012), Peersman and Van Robays (2012), Charnavoki and Dolado (2014) and Bjørnland and Thorsrud (2016) for both oil importing and exporting countries. Still, more recent studies emphasize that oil-specific shocks (i.e., supply) also have a role as a driving force once one allows for different responses across countries, see Aastveit, Bjørnland and Thorsrud (2015) and Caldara, Cavallo and Iacoviello (2016).
} 
these periods of heightened macroeconomic volatility have been briefer, maybe because a more credible monetary policy regime has also been in place since 1982/1983, responding more strongly to inflation.

Going forward, if indeed the recurrent spikes in oil prices are causal factors contributing to economic downturns, the Federal Reserve should pay attention to the short-run implications. We find no evidence that the effects of these spikes have been smaller since monetary policy became more credible. Quite the contrary. Thus, the evidence presented here suggests that the Federal Reserve should give careful consideration to the possible consequences of shocks to commodity prices when designing monetary policy.

The remainder of the paper is structured as follows. Section 2 describes the NewKeynesian model, while the general framework for the Markov Switching model is presented in Section 3. In Section 4 we present the results using our model, while Section 5 shows that the results are robust to some alternative specifications. Section 6 concludes.

\section{A regime-switching New-Keynesian model}

We set up a medium-scale DSGE model with nominal rigidities in the spirit of Christiano, Eichenbaum and Evans (2005) and Smets and Wouters (2007). We model oil production as an individual sector located outside the U.S. Oil is introduced into the model through the production function in the intermediate goods sector. Below we specify the main equations of the model. Additional details on the DSGE model can be found in the online Appendix, while Section 3 gives details on the Markov switching framework.

\section{HOUSEHOLDS}

Households maximize lifetime utility, given by

$$
\mathcal{U}_{0}=\sum_{t=0}^{\infty} \beta^{t} z_{t}\left\{\frac{\left(\frac{C_{t}-\chi \bar{C}_{t-1}}{A_{t}^{C}}\right)^{1-\sigma}}{1-\sigma}-\kappa_{t} \frac{n_{t}^{1+\vartheta}}{1+\vartheta}\right\}
$$

where $C_{t}$ is consumption and $n_{t}$ is hours worked. ${ }^{4}$ The parameter $\beta$ is the subjective discount factor, $\sigma$ is the intertemporal elasticity of substitution, $\chi$ is a parameter governing the degree of habit persistence, and $\vartheta$ is the inverse of the Frisch labor supply elasticity. Consumption is a CES aggregate of different varieties given by $C_{t} \equiv\left(\int_{0}^{1} C_{t}(i)^{\frac{\epsilon-1}{\epsilon}} d i\right)^{\frac{\epsilon}{\epsilon-1}}$, where $\epsilon$ is the elasticity of substitution between the various goods. $\bar{C}_{t}$ is average consumption and $A_{t}^{C}$ is a composite of non-stationary shocks to be defined later. $z_{t}$ is an

\footnotetext{
${ }^{4}$ Note that throughout the paper, we use capital letters for non-stationary variables and small letters for stationary variables.
} 
intertemporal preference shifter and $\kappa_{t}$ is a labor preference shifter, given by

$$
\begin{aligned}
z_{t} & =z_{t-1}^{\rho_{z}} z^{1-\rho_{z}} \exp \left(\sigma_{z} \varepsilon_{z, t}\right), \\
\kappa_{t} & =\kappa_{t-1}^{\rho_{\kappa}} \kappa^{1-\rho_{\kappa}} \exp \left(\sigma_{\kappa} \varepsilon_{\kappa, t}\right) .
\end{aligned}
$$

Both the intertemporal preference shock, $\varepsilon_{z, t}$ and the labor preference shock $\varepsilon_{\kappa, t}$ have a constant volatility. The household maximizes utility subject to a budget constraint given by

$$
P_{t} C_{t}+P_{t} I_{K, t}+D_{t-1} r_{t-1}+P_{t} T A X_{t}=W_{t} n_{t}+R_{K, t} K_{t-1}+D_{t}+D I V_{t},
$$

where $P_{t}$ is the domestic price index given by $P_{t} \equiv\left(\int_{0}^{1} P_{t}(i)^{1-\epsilon} d i\right)^{\frac{1}{1-\epsilon}} \cdot I_{K, t}$ is investments in capital, $D_{t-1}$ is bond holdings at the beginning of period $t$, and $r_{t-1}$ is the gross return on these bonds. $T A X_{t}$ is taxes paid, $W_{t}$ is the wage rate, $K_{t-1}$ is the amount of capital at the beginning of period $t$, and $R_{K, t}$ is the return on this capital. $D I V_{t}$ is firm profits. Capital accumulation is given by

$$
K_{t}=(1-\delta) K_{t-1}+A_{t}^{I K}\left[1-\frac{\phi_{k}}{2}\left(\frac{I_{K, t}}{I_{K, t-1}}-\exp \left(g_{i k}\right)\right)^{2}\right] I_{K, t}
$$

where $\delta$ is the capital depreciation rate, $\phi_{k}$ is a parameter governing the capital adjustment cost and $g_{i k}$ is the growth rate of investments in capital. $A_{t}^{I K}$ is investment technology given by the following process

$$
A_{t}^{I K}=A_{t-1}^{I K} \exp \left(g_{a i k}+\sigma_{a i k}\left(\mathcal{S}_{t}^{\mathrm{Vol}}\right) \varepsilon_{a i k, t}\right)
$$

where $g_{a i k}$ is the growth rate of investment technology. We will allow for two regimes for macroeconomic volatility, defined by

$$
\mathcal{S}_{t}^{\text {Vol }} \in\{\text { Low volatility, High volatility }\}
$$

The volatility of the investment specific shock, $\sigma_{a i k}$, follows the macroeconomic volatility chain, $\mathcal{S}_{t}^{\text {Vol }}$, and can switch between two possible values. Note that we will allow other shocks to also follow the macroeconomic volatility chain, see below. We will restrict all parameters that follow this Markov chain to switch at the same time and in the same direction.

\section{FIRMS}

We have an intermediate goods sector producing an output good using oil, capital, and labor. The production function is given by

$$
Y_{t}=A_{t}\left[O_{t}^{\varrho} K_{t-1}^{1-\varrho}\right]^{\alpha} n_{t}^{1-\alpha}
$$


where $O_{t}$ is oil input in production. $(1-\alpha)$ is the share of labor in output and $\varrho$ is the share of oil relative to capital. ${ }^{5} A_{t}$ is a technology process given by

$$
A_{t}=A_{t-1} \exp \left(g_{a}+\sigma_{a}\left(\mathcal{S}_{t}^{\mathrm{Vol}}\right) \varepsilon_{a, t}\right)
$$

where $g_{a}$ is the growth rate of neutral technology. As for the investment-specific shock, we will allow the volatility of the neutral technology shock, $\sigma_{a}$, to also take two possible values, following the same macro volatility Markov chain, $\mathcal{S}_{t}^{\text {Vol }}$. Finally, the intermediate goods are bundled together according to the following technology $Y_{t}=\left(\int_{0}^{1} Y_{i, t}^{\frac{\varepsilon-1}{\varepsilon}} d i\right)^{\frac{\varepsilon}{\varepsilon-1}}$, where $\varepsilon$ is the elasticity of substitution between different varieties.

We use the Rotemberg model for price setting, assuming that the monopolistic firms face a quadratic cost of adjusting nominal prices. The rate of inflation is given by $\pi_{t}=$ $P_{t} / P_{t-1}$. The firms set prices to maximize lifetime profits, which gives the following first order condition

$$
\begin{aligned}
0= & \frac{\Psi_{t}}{P_{t}}\left(\frac{\epsilon}{\epsilon-1}\right)-\exp \left(\sigma_{\pi}\left(\mathcal{S}_{t}^{\mathrm{Vol}}\right) \varepsilon_{t}^{\pi}\right)-\left(\frac{\omega}{\epsilon-1}\right) \pi_{t}\left[\pi_{t}-\ddot{\pi}_{t}\right] \\
& +\mathbb{E}_{t}\left\{\left(\frac{\omega}{\epsilon-1}\right) m_{t} \frac{Y_{t+1}}{Y_{t}}\left(\pi_{t+1}\right)^{2}\left[\pi_{t+1}-\ddot{\pi}_{t+1}\right]\right\},
\end{aligned}
$$

where $\Psi_{t}$ is real marginal costs, $m_{t}$ is the stochastic discount factor between period $t$ and $t+1$, and $\omega$ governs the cost of adjusting prices. We have a markup shock, $\varepsilon_{t}^{\pi}$, the volatility of which can switch according to the macroeconomic volatility chain $\mathcal{S}_{t}^{\text {Vol }}$. $\ddot{\pi}_{t}$ gives the indexation of prices to the previous period, defined as

$$
\ddot{\pi}_{t} \equiv \pi_{t-1}^{\gamma_{\pi}} \bar{\pi}^{1-\gamma_{\pi}}
$$

where $\bar{\pi}$ is steady state inflation and $\gamma_{\pi}$ governs the degree of indexation to the past price level. We allow switching in the volatility of the stochastic subsidy shock $\left(\sigma_{\pi}\right)$, following the same macro volatility Markov chain $\mathcal{S}_{t}^{\text {Vol }}$.

\section{WAGE SETTING}

We also use the Rotemberg model for wage setting, assuming that the unions face a quadratic cost of adjusting nominal wages. Wage inflation is given by $\pi_{t}^{w}=W_{t} / W_{t-1}$. Unions choose wages to maximize wage earnings, which gives the following first order condition

$$
\begin{aligned}
0= & \frac{v}{v-1} z_{t} \kappa_{t} \frac{n_{t}^{\vartheta}}{\Lambda_{t} W_{t}}-1-\frac{\xi}{v-1} \pi_{t}^{w}\left[\pi_{t}^{w}-\ddot{\pi}_{t}^{w}\right] \\
& +\mathbb{E}_{t}\left\{\beta \frac{\Lambda_{t+1}}{\Lambda_{t}} \frac{\xi}{v-1} \frac{n_{t+1}}{n_{t}}\left(\pi_{t+1}^{w}\right)^{2}\left[\pi_{t+1}^{w}-\ddot{\pi}_{t+1}^{w}\right]\right\}
\end{aligned}
$$

\footnotetext{
${ }^{5}$ The share of oil in production is given by $\alpha \varrho$.
} 
where $v$ is the elasticity of substitution between various types of labor, $\xi$ governs the cost of adjusting prices, and $\Lambda_{t}$ is the Lagrange multiplier from the labor union's optimization problem. We assume this process is given by

$$
\ddot{\pi}_{t}^{w} \equiv\left(\pi_{t-1}^{w}\right)^{\gamma_{w}}\left(\bar{\pi}^{w}\right)^{1-\gamma_{w}},
$$

where $\gamma_{w}$ governs the degree of indexation to the past wage level.

\section{MONETARY AND FISCAL POLICY}

Monetary policy responds to inflation and output following a Taylor rule:

$$
r_{t}=r_{t-1}^{\rho_{r}\left(\mathcal{S}_{t}^{\mathrm{Pol}}\right)}\left[r\left(\frac{Y_{t}}{A_{t}^{C} \bar{y}}\right)^{\kappa_{Y}\left(\mathcal{S}_{t}^{\mathrm{Pol}}\right)}\left(\frac{\pi_{t}}{\bar{\pi}}\right)^{\kappa_{\pi}\left(\mathcal{S}_{t}^{\mathrm{Pol}}\right)}\right]^{1-\rho_{r}\left(\mathcal{S}_{t}^{\mathrm{Pol}}\right)} \exp \left(\sigma_{r} \varepsilon_{r, t}\right),
$$

where $\kappa_{\pi}$ and $\kappa_{y}$ are parameters governing the central bank's responsiveness to inflation and the output gap respectively. The parameter $\rho_{r}$ gives the rate of interest rate smoothing over time and $\epsilon_{r, t}$ is a monetary policy shock.

Importantly, we allow all parameters that the monetary authorities have control over to switch throughout the sample. That is, we allow for two monetary policy regimes given by

$$
\mathcal{S}_{t}^{\text {Pol }} \in\{\text { Hawkish, Dovish }\}
$$

We define the "Hawkish" regime as the episodes where the monetary authorities respond most to inflation. The policy parameters follow the same chain, $\mathcal{S}_{t}^{\text {Pol }}$, implying they will switch together (albeit not necessarily in the same direction).

For fiscal policy, we assume government consumption is financed by taxes so that $T A X_{t}=G_{t}$. Detrended government consumption follows an $\operatorname{AR}(1)$ process

$$
\frac{G_{t}}{A_{t}^{C}}=\left(\frac{G_{t-1}}{A_{t-1}^{C}}\right)^{\rho_{G}} g^{1-\rho_{G}} \exp \left(\sigma_{g} \varepsilon_{g, t}\right) .
$$

\section{OIL SECTOR}

We model the oil price as being determined in an individual sector that can be thought of as being located outside the U.S. Oil prices can be affected by two type of shocks; Shocks to world demand and oil-specific (supply) shocks. This follows Kilian (2009), which finds world demand to be an important source of variation in oil prices, in particular in the recent oil price boom. Furthermore, Kilian (2009) shows that if oil prices increase due to surges in demand for oil (rather than disruptions of supply capacity, see, e.g., Hamilton (1983)), global economic activity will be positively affected, at least in the short run.

To identify the two shocks, we will model growth in world activity and the real oil price jointly in a bi-variate VAR model given by

$$
\boldsymbol{A}_{0}\left[\begin{array}{c}
\Delta \log \left(G D P_{t}^{\mathrm{W}}\right) \\
\log \left(p_{o, t}\right)
\end{array}\right]=\boldsymbol{c}+\sum_{j=1}^{p} \boldsymbol{A}_{j}\left[\begin{array}{c}
\Delta \log \left(G D P_{t-j}^{\mathrm{W}}\right) \\
\log \left(p_{o, t-j}\right)
\end{array}\right]+\left[\begin{array}{c}
\sigma_{t}^{\mathrm{W}} \varepsilon_{W, t} \\
\sigma_{t}^{\mathrm{Oil}}\left(\mathcal{S}_{t}^{\mathrm{Oil}}\right) \varepsilon_{o, t}
\end{array}\right]
$$


where $p_{o, t}$ is the real oil price and $\triangle G D P_{t}^{\mathrm{W}}$ is the growth rate of world GDP. $\boldsymbol{A}_{0}$ is lower triangular matrix, implying a lagged response of activity to an oil price shock, whereas oil prices can respond contemporaneously to a world demand shock. ${ }^{6}$ We allow the volatility of the oil price shock to change according to a Markov chain given by

$$
\mathcal{S}_{t}^{\text {Oil }} \in\{\text { Low oil price volatility, High oil price volatility }\}
$$

Finally, $A_{t}^{C}$ is defined as

$$
A_{t}^{C}=A_{t}^{\frac{1}{1-\alpha}}\left(A_{t}^{I K}\right)^{\frac{\alpha}{1-\alpha}}
$$

This is the trend followed by the consumption process. It is a composite of the technology shock $A_{t}$ and the investment-specific technology shock $A_{t}^{I K}$. These two shocks are the ones making real variables nonstationary in the system. Intuitively then, detrending/stationarizing those real variables requires some combination of the two shocks.

\section{The Markov Switching Rational Expectation frame- work}

Many solution approaches, like Farmer, Waggoner and Zha (2011), Svensson and Williams (2007) or Cho (2014), start out with a linearized model and then apply Markov switching to the parameters. This strategy is reasonable as long as one takes a linear specification as the structural model. When the underlying structural model is nonlinear, however, the agents are aware of the nonlinear nature of the system and of the switching process. This has implications for the solutions based on approximation and for the decision rules. Following Maih (2014), the model outlined above can be cast in a general Markov Switching DSGE (MSDSGE) framework

$$
\mathbb{E}_{t} \sum_{\mathcal{S}_{t+1}=1}^{h} p_{\mathcal{S}_{t}, \mathcal{S}_{t+1}} \boldsymbol{d}_{\mathcal{S}_{t}}\left(\boldsymbol{x}_{t+1}\left(\mathcal{S}_{t+1}\right), \boldsymbol{x}_{t}\left(\mathcal{S}_{t}\right), \boldsymbol{x}_{t-1}, \boldsymbol{\varepsilon}_{t}\right)=0
$$

where $\mathbb{E}_{t}$ is the expectation operator, $\boldsymbol{d}_{\mathcal{S}_{t}}: \mathbb{R}^{n_{v}} \longrightarrow \mathbb{R}^{n_{d}}$ is a $n_{d} \times 1$ vector of possibly nonlinear functions of their arguments, $\mathcal{S}_{t}=1,2, . ., h$ is the regime at time $t, \boldsymbol{x}_{t}$ is a $n_{x} \times 1$ vector of all the endogenous variables, $\varepsilon_{t}$ is a $n_{\varepsilon} \times 1$ vector of shocks with $\varepsilon_{t} \sim N\left(0, \boldsymbol{I}_{n_{\varepsilon}}\right)$, $p_{\mathcal{S}_{t}, \mathcal{S}_{t+1}}$ is the transition probability for going from regime $\mathcal{S}_{t}$ in the current period to

\footnotetext{
${ }^{6}$ This restriction follows Kilian (2009). Note, however, that Kilian (2009) allows for three shocks: Oil supply, aggregate demand and oil-specific demand. By including only two shocks, we have effectively aggregated together oil supply and oil-specific shocks. This is plausible, given the small role of oil supply in various historical periods, see Kilian (2009).
} 
regime $\mathcal{S}_{t+1}=1,2, . ., h$ in the next period and is such that $\sum_{\mathcal{S}_{t+1}=1}^{h} p_{\mathcal{S}_{t}, \mathcal{S}_{t+1}}=1 .^{7}$ In this paper, we will allow $h=8$. This follows from the model set up above, where we have specified two monetary policy states (hawkish and dovish), two macro volatility states (high and low), and two oil price volatility states (high and low), which combined gives eight possible regimes (see the online appendix for details).

We are interested in solutions of the form

$$
\boldsymbol{x}_{t}\left(\mathcal{S}_{t}\right)=\mathcal{T}^{\mathcal{S}_{t}}\left(\boldsymbol{z}_{t}\right)
$$

where $\boldsymbol{z}_{t}$ is an $n_{z} \times 1$ vector of state variables.

In general, there is no analytical solution to $(17)$ even in cases where $\boldsymbol{d}_{\mathcal{S}_{t}}$ is linear. Maih (2014) develops a perturbation solution technique that allows us to approximate the decision rules in (18). The vector of state variables is then

$$
\boldsymbol{z}_{t} \equiv\left[\begin{array}{ccc}
\boldsymbol{x}_{t-1}^{\prime} & \sigma & \boldsymbol{\varepsilon}_{t}^{\prime}
\end{array}\right]^{\prime}
$$

where $\sigma$ is a perturbation parameter.

For the purpose of estimation, in this paper we restrict ourselves to a first-order perturbation $^{8}$. We then approximate $\mathcal{T}^{\mathcal{S}_{t}}$ in (18) with a solution of the form

$$
\mathcal{T}^{\mathcal{S}_{t}}(\boldsymbol{z}) \simeq \mathcal{T}^{\mathcal{S}_{t}}\left(\overline{\boldsymbol{z}}_{\mathcal{S}_{t}}\right)+\mathcal{T}_{z}^{\mathcal{S}_{t}}\left(\boldsymbol{z}_{t}-\overline{\boldsymbol{z}}_{\mathcal{S}_{t}}\right)
$$

where $\overline{\boldsymbol{z}}_{\mathcal{S}_{t}}$ is the steady state values of the state variables in regime $\mathcal{S}_{t}$.

This solution is computed using the Newton algorithm of Maih (2014), which is similar in spirit but distinct from that of Farmer, Waggoner and Zha (2011), henceforward FWZ. We use Maih's algorithm because it is more general, more efficient and more robust than that of FWZ. As demonstrated in Maih (2014), the efficiency of Maih's algorithm comes from several factors. First, Maih's algorithm solves a smaller system than FWZ. Because the FWZ algorithm is a direct extension of Sims (2002), FWZ have to solve for expectational errors in addition to the other endogenous variables in the system, which Maih's algorithm does not do. Second, Maih's strategy is to build the Newton solution using directional derivatives. This approach permits to see that the problem of finding the Newton step can be recast into solving a system of generalized coupled Sylvester equations. Such systems can be solved without building and storing large Kronecker products and without inverting large matrices. This makes Maih's algorithm suitable

\footnotetext{
${ }^{7}$ Although in this paper we only consider exogenous or constant probabilities, the toolbox we use for our computations allows for endogenous or time-varying transition probabilities as well. In that case, however, the user has to explicitly define the functional form and the variables entering the function, which is far from obvious.

${ }^{8}$ In the RISE toolbox, perturbation solutions can be computed to orders as high as five. The toolbox also includes algorithms for the filtering of nonlinear regime-switching models.
} 
for large systems. ${ }^{9}$ The FWZ algorithm, on the other hand, does require building and storing large Kronecker products and inverting a large matrix arising in the calculation of the Newton step. Third, the FWZ algorithm breaks down when the coefficient matrix on the contemporaneous terms is singular. When this occurs, FWZ have to resort to an alternative procedure that slows down their algorithm even further. This problem does not occur in Maih's algorithm. ${ }^{10}$

This type of solution in (19) makes it clear that the framework allows the model economy to be in different regimes at different points in time, with each regime being governed by certain rules specific to the regime. In that case the traditional stability concept for constant-parameter linear rational expectations models, the Blanchard-Kahn conditions, cannot be used. Instead, following the lead of Svensson and Williams (2007) and Farmer, Waggoner and Zha (2011) among others, this paper uses the concept of mean square stability (MSS) borrowed from the engineering literature, to characterize stable solutions.

Consider the MSDSGE system whose solution is given by equation (19) and with constant transition probability matrix $\boldsymbol{Q}$ such that $Q_{\mathcal{S}_{t}, \mathcal{S}_{t+1}}=p_{\mathcal{S}_{t}, \mathcal{S}_{t+1}}$. We can expand the solution in (19) and re-write it as

$$
\boldsymbol{x}_{t}(\boldsymbol{z})=\mathcal{T}^{\mathcal{S}_{t}}\left(\overline{\boldsymbol{z}}_{\mathcal{S}_{t}}\right)+\mathcal{T}_{z, x}^{\mathcal{S}_{t}}\left(\boldsymbol{x}_{t-1}-\mathcal{T}^{\mathcal{S}_{t}}\left(\overline{\boldsymbol{z}}_{\mathcal{S}_{t}}\right)\right)+\mathcal{T}_{z, \sigma}^{\mathcal{S}_{t}} \sigma+\mathcal{T}_{z, \varepsilon^{0}}^{\mathcal{S}_{t}} \boldsymbol{\varepsilon}_{t}
$$

This system and thereby (19) is MSS if for any initial condition $x_{0}$, there exist a vector $\boldsymbol{\mu}$ and a matrix $\boldsymbol{\Sigma}$ independent of $x_{0}$ such that $\lim _{t \rightarrow \infty}\left\|\mathbb{E} \boldsymbol{x}_{t}-\boldsymbol{\mu}\right\|=\mathbf{0}$ and $\lim _{t \rightarrow \infty}\left\|\mathbb{E} \boldsymbol{x}_{t} \boldsymbol{x}_{t}^{\prime}-\boldsymbol{\Sigma}\right\|=\mathbf{0}$. Hence the covariance matrix of the process is bounded. As shown by Gupta, Murray and Hassibi (2003) and Costa, Fragoso and Marques (2005), a necessary and sufficient condition for MSS is that matrix $\Upsilon$, as defined in (20), has all its eigenvalues inside the unit circle, ${ }^{11}$

$$
\Upsilon \equiv\left(\boldsymbol{Q} \otimes \boldsymbol{I}_{n_{x}^{2} \times n_{x}^{2}}\right)\left[\begin{array}{ccc}
\mathcal{T}_{z, x}^{1} \otimes \mathcal{T}_{z, x}^{1} & & \\
& \ddots & \\
& & \mathcal{T}_{z, x}^{h} \otimes \mathcal{T}_{z, x}^{h}
\end{array}\right]
$$

Having specified the New-Keynesian model and the Markov Switching framework, we now turn to describe the data and then to estimate the model.

\footnotetext{
${ }^{9}$ The algorithm has been used in the solving of a system of upwards of 300 equations.

${ }^{10}$ In addition to being more efficient, Maih's algorithms are also more general and can solve problems that the FWZ algorithm cannot solve. See Maih (2014) for further details.

${ }^{11}$ It is not very hard to see that a computationally more efficient representation of $\Upsilon$ is given by: $\left[\begin{array}{cccc}p_{1,1}\left(\mathcal{T}_{z, x}^{1} \otimes \mathcal{T}_{z, x}^{1}\right) & p_{1,2}\left(\mathcal{T}_{z, x}^{2} \otimes \mathcal{T}_{z, x}^{2}\right) & \cdots & p_{1, h}\left(\mathcal{T}_{z, x}^{h} \otimes \mathcal{T}_{z, x}^{h}\right) \\ p_{2,1}\left(\mathcal{T}_{z, x}^{1} \otimes \mathcal{T}_{z, x}^{1}\right) & p_{2,2}\left(\mathcal{T}_{z, x}^{2} \otimes \mathcal{T}_{z, x}^{2}\right) & \cdots & p_{2, h}\left(\mathcal{T}_{z, x}^{h} \otimes \mathcal{T}_{z, x}^{h}\right) \\ \vdots & \vdots & & \vdots \\ p_{h, 1}\left(\mathcal{T}_{z, x}^{1} \otimes \mathcal{T}_{z, x}^{1}\right) & p_{h, 2}\left(\mathcal{T}_{z, x}^{2} \otimes \mathcal{T}_{z, x}^{2}\right) & \cdots & p_{h, h}\left(\mathcal{T}_{z, x}^{h} \otimes \mathcal{T}_{z, x}^{h}\right)\end{array}\right]$
} 


\subsection{Data and Bayesian estimation}

We estimate the parameters in the model with Bayesian methods using the RISE toolbox in Matlab. The equations of the system are coded up nonlinearly in their stationary form. The software takes the file containing the equations and automatically computes the perturbation solution as well as the state-space form that is used for the likelihood computation. For a regime-switching model like ours, the computation of the likelihood has to be done via a filtering algorithm due to the presence of unobservable variables. An exact filtering procedure that will track all possible histories of regimes is infeasible. One solution described by Kim and Nelson (1999b) consists of collapsing (averaging) the forecasts for various regimes in order to avoid an explosion of the number of paths. An alternative approach, the one we follow, is to collapse the updates in the filtering procedure. This approach yields numerically similar results as the Kim and Nelson filter but has the advantage of being computationally more efficient.

The estimation is based on the 1965Q1-2014Q1 quarterly time-series observations on the eight time series: the federal funds rate, oil price inflation, CPI-based inflation, GDP growth, investment growth, wage inflation, consumption growth and the growth rate of world activity. The data were downloaded from the St. Louis FRED database. More details about sources and transformations are given in the online Appendix.

Besides the model equations and the data, another input has to be provided for us to do Bayesian estimation: the prior information on the parameters. We fix a subset of parameters following a calibration and estimate the rest conditional on the fixed ones. For the calibrated parameters then, the government spending-to-GDP ratio is set to $0.16 .^{12}$

Rather than setting means and standard deviations for our parameters as it is customarily done, we set our priors using quantiles of the distributions. More specifically, we use the 90 percent probability intervals of the distributions to uncover the underlying hyperparameters. In some cases, such as for the inverse gamma distribution, the hyperparameters found are such that the distribution has no first and second moments. For numerical reasons, some of the estimated parameters are estimated indirectly via transformations.

We let the transform of the steady state inflation, $400 \log \left(\pi_{s s}\right)$, follow a gamma distribution such that the quantiles 1 and 5 cover 90 percent of the probability interval. The transform of the discount factor, $100(1 / \beta-1)$, follows a beta distribution with quantiles 0.2 and 0.4 covering the 90 percent probability interval. All the standard deviations of the model follow an inverse gamma distribution with quantiles 0.0001 and 2 covering the 90 percent probability interval. This is also the case for the measurement errors on consumption growth, investment growth and wage inflation. The transition probabilities for the

\footnotetext{
${ }^{12}$ Following http://data.worldbank.org/indicator/NE.CON.GOVT.ZS.
} 
off-diagonal terms of each transition matrix follow a beta distribution with 0.009 to 0.411 covering the 90 percent probability interval. The transforms of the adjustment costs for capital $\left(\phi_{k} / 200\right)$, wages $(\omega / 200)$ and prices $(\xi / 200)$ follow a beta distribution with 0.2 to 0.8 covering the 90 percent probability interval. The beta distribution is also used both for the interest rate smoothing in the Taylor rule and for the persistence parameters for shock processes with 0.0256 to 0.7761 covering the 90 percent probability interval. Besides the interest rate smoothing, the other policy parameters entering the Taylor rule $\left(\kappa_{\pi}\right.$ and $\kappa_{y}$ ) follow a gamma distribution with different specifications depending on the regime. The transforms of the Inverse Frisch Elasticity $(\vartheta-1)$, the Elasticity of Substitution between products $(\epsilon-1)$, the elasticity of substitution between labor inputs $(v-1)$ and the inverse intertemporal elasticity of substitution $(\sigma-1)$ follow a gamma distribution with quantiles 1 and 8. Finally, we estimate the parameters governing the oil - macroeconomic relationship jointly with the other parameters.

The full list of our prior assumptions are reported in Table 1 along with the posteriors. To compute the posterior kernel, the software (RISE) combines the (approximated) likelihood function with the prior information. The sampling of the posterior distribution is not an easy task and there is no guarantee, in a complicated model like ours in which the posterior density function is multimodal ${ }^{13}$, that the posterior distribution will be adequately sampled or that the optimization routines used will find the global peak of the posterior distribution of the parameters. We exploit the stochastic search optimization routines of the RISE toolbox to estimate the mode. With a mode or starting point in hand, our strategy to simulate the posterior distribution is to run 5 parallel chains of the Metropolis Hastings with continuous adaptation of both the covariance matrix and the scale parameter. The scale parameter in particular is adapted so as to maintain an acceptance ratio of about 0.234 . Each chain is iterated 1 million times and every 5 th draw is saved, resulting in a total of 200,000 draws per chain. These draws are then used for inference.

The whole process is computationally rather intensive. For a given parameter draw, the steady state for each regime has to be computed. The first-order perturbation solution of model is then computed following the Newton algorithms described in Maih (2014), setting the convergence criterion to the square root of machine epsilon. If a solution is found, it is checked for MSS. If the MSS test is passed, the likelihood of the data is

\footnotetext{
${ }^{13}$ The estimation procedure in RISE allows us to add restrictions on the parameters. We exploit this feature to identify the regimes. In particular, we identify the first regime of the oil price volatility chain as a regime of high volatility by imposing that the standard deviation in the first state to be bigger than in the second state. Similar schemes are used to distinguish the hawkish from the dovish regime for the policy Markov chain and the high from the low macroeconomic volatility regime in the macroeconomic volatility Markov chain.
} 
computed using the solution found and then combined with the prior distribution of the parameters. This process, which has to be repeated millions of times, takes several weeks to complete. We monitor convergence using various tools such as trace plots as well as the Potential Scale Reduction Factor statistic as outlined in Gelman et al. (2004).

\section{Results}

We present here the results from estimating the Markov Switching Rational Expectation New-Keynesian model allowing for regime switches in macroeconomic volatility, oil price volatility and monetary policy responses. We first report parameter estimates, before giving details on the regime probabilities and the impulse responses. Finally we examine the historical contribution of the various structural shocks to the observed time series, emphasizing the contribution of oil and non-oil shocks.

\subsection{Parameter estimates}

Table 1 displays the posterior (modes and medians) for the DSGE parameters and the offdiagonal terms of the transition matrix. Starting with the parameters governing the high and low macroeconomic volatility regime, we find a clear difference between the various regimes. In particular, the standard deviation of the macro volatility shocks, $\sigma_{a i k}, \sigma_{a}$ and $\sigma_{\pi}$, is estimated to be 2-3 times higher in the high macro volatility regime than in the low macro volatility regime. Overall we find the probability of moving from high to low macro volatility regimes to be twice as high as the probability of moving from the low to high volatility regime.

Concerning the standard deviation of the oil price shocks $\sigma_{o}$, we confirm a substantial difference between the high and low oil price volatility regimes In particular, the standard deviation shock to the oil price is estimated to be 32 percent in the high oil price volatility regime compared with 7 percent in the low volatility regime. Furthermore, the probability of moving from the high to the low oil price volatility regime is three times as high as the probability of mowing from the low to the high oil price volatility regime.

Finally, we find a substantial difference between the parameters governing the policy rule. Under the high policy response regime, the FFR reacts strongly to inflation; $\kappa_{\pi}$ is estimated to be 2.27 , while it is only 0.5 in the low response regime. The response to the output gap, $\kappa_{y}$, however, moves in the other direction; FFR responds less to the output gap in the high response regime than in the low response regime. The interest rate smoothing parameter, $\rho_{r}$, is estimated to be 0.88 in the high response regime, and just slightly lower, 0.76 , in the low response regime. Still this implies that the relative difference between the parameters in the high and low policy regimes will be even larger. 
Table 1: Priors and posteriors

\begin{tabular}{|c|c|c|c|c|c|c|c|}
\hline \multirow[b]{2}{*}{ Parameter } & \multicolumn{3}{|c|}{ Prior } & \multicolumn{4}{|c|}{ Posterior } \\
\hline & Distr. & $5 \%$ & $95 \%$ & Mode & Median & $5 \%$ & $95 \%$ \\
\hline $400 \log \left(\pi_{s s}\right)$ & G & 1 & 5 & 4.051 & 4.123 & 3.969 & 4.507 \\
\hline$[1+0.01 \beta]^{-1}$ & B & 0.2 & 0.4 & 0.1823 & 0.1737 & 0.1155 & 0.3374 \\
\hline$\vartheta-1$ & G & 1 & 8 & 1.217 & 1.317 & 1.075 & 1.973 \\
\hline$\epsilon-1$ & G & 1 & 8 & 11.83 & 11.75 & 11.65 & 11.85 \\
\hline$v-1$ & G & 1 & 8 & 1.828 & 2.194 & 1.845 & 2.311 \\
\hline$\sigma-1$ & G & 1 & 8 & 0.8069 & 0.8924 & 0.7882 & 1.001 \\
\hline $0.02 \phi_{k}$ & B & 0.2 & 0.8 & 0.0285 & 0.0203 & 0.0142 & 0.0297 \\
\hline $0.02 \omega$ & B & 0.2 & 0.8 & 0.604 & 0.4414 & 0.3293 & 0.613 \\
\hline $0.02 \xi$ & B & 0.2 & 0.8 & 0.4969 & 0.5249 & 0.4055 & 0.6231 \\
\hline $100 g_{a i k}$ & G & 0.3074 & 1.537 & 0.5298 & 0.4829 & 0.3005 & 0.7024 \\
\hline $100 g_{a}$ & G & 0.3095 & 1.547 & 0.6192 & 0.4791 & 0.3875 & 0.604 \\
\hline $100 g_{W}$ & G & 0.1797 & 0.8983 & 0.6005 & 0.6401 & 0.5195 & 0.927 \\
\hline$\gamma_{\pi}$ & B & 0.0256 & 0.7761 & 0.0175 & 0.0222 & 0.0011 & 0.0581 \\
\hline$\gamma_{w}$ & B & 0.0256 & 0.7761 & 0.1801 & 0.1066 & 0.0179 & 0.3106 \\
\hline$\chi$ & B & 0.0256 & 0.7761 & 0.7972 & 0.7914 & 0.7493 & 0.8303 \\
\hline$\rho_{g}$ & B & 0.0256 & 0.7761 & 0.1971 & 0.2593 & 0.1188 & 0.3643 \\
\hline$\rho_{\kappa}$ & B & 0.3 & 0.7 & 0.4553 & 0.4574 & 0.2811 & 0.5386 \\
\hline$\rho_{z}$ & B & 0.0256 & 0.7761 & 0.3787 & 0.7469 & 0.3573 & 0.9815 \\
\hline$\varrho$ & B & 0.0256 & 0.7761 & 0.0426 & 0.0623 & 0.0382 & 0.0922 \\
\hline$p_{-}\{$High vol, Low vol $\}$ & B & 0.009 & 0.411 & 0.116 & 0.0815 & 0.0155 & 0.3195 \\
\hline$p_{-}\{$Low vol, High vol $\}$ & B & 0.009 & 0.411 & 0.1032 & 0.0764 & 0.0138 & 0.2017 \\
\hline$p_{-}\{$High oil, Low oil $\}$ & B & 0.009 & 0.411 & 0.3374 & 0.2758 & 0.1453 & 0.3389 \\
\hline$p_{-}\{$Low oil, High oil $\}$ & B & 0.009 & 0.411 & 0.0766 & 0.0578 & 0.0318 & 0.1043 \\
\hline$p_{-}\{$Hawkish, Dovish $\}$ & B & 0.009 & 0.411 & 0.0587 & 0.0627 & 0.0493 & 0.0962 \\
\hline$p_{-}\{$Dovish, Hawkish $\}$ & $\mathrm{B}$ & 0.009 & 0.411 & 0.0933 & 0.0846 & 0.0597 & 0.1103 \\
\hline$\sigma_{\kappa}$ & IG & 0.0001 & 2 & 0.0004 & 0.0004 & 0.0001 & 0.0017 \\
\hline$\sigma_{g}$ & IG & 0.0001 & 2 & 0.0002 & 0.0004 & 0.0001 & 0.0015 \\
\hline$\sigma_{r}$ & IG & 0.0001 & 2 & 0.0024 & 0.0024 & 0.0022 & 0.0026 \\
\hline$\sigma_{z}$ & $\mathrm{IG}$ & 0.0001 & 2 & 0.0001 & 0.0080 & 0.0001 & 0.0298 \\
\hline$\sigma_{W}$ & IG & 0.0001 & 2 & 0.0047 & 0.0046 & 0.0043 & 0.0050 \\
\hline$\sigma_{a i k}\left(\mathcal{S}_{t}^{\mathrm{Vol}}=\mathrm{High}\right)$ & IG & 0.0001 & 2 & 0.0308 & 0.0286 & 0.0224 & 0.0422 \\
\hline$\sigma_{a i k}\left(\mathcal{S}_{t}^{\mathrm{Vol}}=\right.$ Low $)$ & IG & 0.0001 & 2 & 0.0138 & 0.0128 & 0.0003 & 0.0182 \\
\hline$\sigma_{a}\left(\mathcal{S}_{t}^{\mathrm{Vol}}=\mathrm{High}\right)$ & IG & 0.0001 & 2 & 0.0172 & 0.0151 & 0.0129 & 0.0187 \\
\hline$\sigma_{a}\left(\mathcal{S}_{t}^{\mathrm{Vol}}=\right.$ Low $)$ & IG & 0.0001 & 2 & 0.0082 & 0.0069 & 0.0055 & 0.0090 \\
\hline$\sigma_{\pi}\left(\mathcal{S}_{t}^{\mathrm{Vol}}=\mathrm{High}\right)$ & IG & 0.0001 & 2 & 0.0003 & 0.0006 & 0.0002 & 0.0018 \\
\hline$\sigma_{\pi}\left(\mathcal{S}_{t}^{\mathrm{Vol}}=\right.$ Low $)$ & IG & 0.0001 & 2 & 0.0002 & 0.0002 & 0.0001 & 0.0007 \\
\hline$\sigma_{o}\left(\mathcal{S}_{t}^{\text {Oil }}=\right.$ High $)$ & IG & 0.0001 & 2 & 0.2539 & 0.3118 & 0.2319 & 0.4021 \\
\hline$\sigma_{o}\left(\mathcal{S}_{t}^{\text {Oil }}=\right.$ Low $)$ & IG & 0.0001 & 2 & 0.0695 & 0.0713 & 0.0625 & 0.0803 \\
\hline$\rho_{r}\left(\mathcal{S}_{t}^{\text {Pol }}=\right.$ Hawkish $)$ & B & 0.0256 & 0.7761 & 0.8984 & 0.8913 & 0.8598 & 0.9181 \\
\hline$\rho_{r}\left(\mathcal{S}_{t}^{\text {Pol }}=\right.$ Dovish $)$ & B & 0.0256 & 0.7761 & 0.7095 & 0.7418 & 0.6732 & 0.8327 \\
\hline$\kappa_{\pi}\left(\mathcal{S}_{t}^{\text {Pol }}=\right.$ Hawkish $)$ & G & 0.5 & 3 & 2.378 & 2.308 & 2.009 & 2.464 \\
\hline$\kappa_{\pi}\left(\mathcal{S}_{t}^{\mathrm{Pol}}=\right.$ Dovish $)$ & G & 0.5 & 2 & 0.4856 & 0.6275 & 0.4926 & 0.7277 \\
\hline$\kappa_{y}\left(\mathcal{S}_{t}^{\text {Pol }}=\right.$ Hawkish $)$ & G & 0.05 & 1 & 0.0137 & 0.0139 & 0.0029 & 0.0345 \\
\hline$\kappa_{y}\left(\mathcal{S}_{t}^{\text {Pol }}=\right.$ Dovish $)$ & G & 0.05 & 1 & 0.0057 & 0.0186 & 0.0035 & 0.0741 \\
\hline stderr_DCONS & IG & 0.0001 & 2 & 0.0054 & 0.0051 & 0.0045 & 0.0056 \\
\hline stderr_DINV & IG & 0.0001 & 2 & 0.0324 & 0.0298 & 0.0276 & 0.0322 \\
\hline stderr_DWAGES & IG & 0.0001 & 2 & 0.0144 & 0.0147 & 0.0137 & 0.0157 \\
\hline
\end{tabular}

Note: The following abbreviations are used: Beta distribution (B), Normal distribution (N), Gamma distribution (G), Inverse Gamma distribution (IG). 

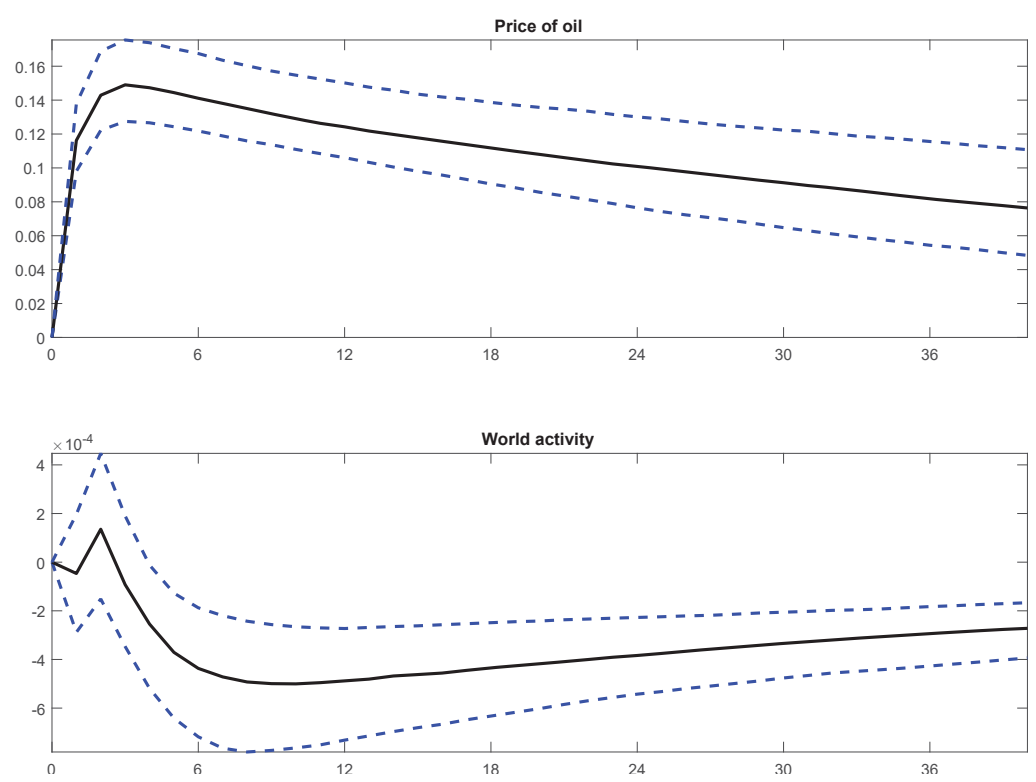

Figure 2: Oil price shock

Note: The figure graphs the generalized impulse responses to an oil price shock (that is normalized to increase oil prices)

Regarding the oil - macroeconomic relationship, rather than discussing the estimated parameters, Figures $2-3$ summarize the properties by displaying the model implied impulse responses from respectively the oil price shock and the world demand shock to oil prices and global activity. ${ }^{14}$ The figures show that while a shock to oil prices has a temporarily negative effect on global activity, a world demand shock, that increases global activity boosts oil prices temporarily. Hence, and in line with Kilian (2009) when analyzing the effect of an oil price shock on the U.S. economy, it seems important to separate the effect of a world demand shock from the other (supply-side driven) oil market shocks.

\subsection{Smoothed state probabilities}

The key output of our model, the smoothed probabilities, are plotted in Figure 4. The figure graphs the median, together with the 68 percent probability bands. Shaded areas are NBER recessions. The top row shows the smoothed probabilities for being in the high macroeconomic volatility state. We identify a state with high volatility in the structural macroeconomic shocks for the periods prior to 1984/1985. That is, from the early 1970s and until the mid 1980s, the economy is mostly in a state of high macroeconomic volatility. From 1984/1985, the economy moves into a low volatility state. The shift from the high to the low volatility state in the middle 1980 s is in line with the findings reported in the

\footnotetext{
${ }^{14}$ See the online appendix for all the parameter estimates based on the VAR.
} 

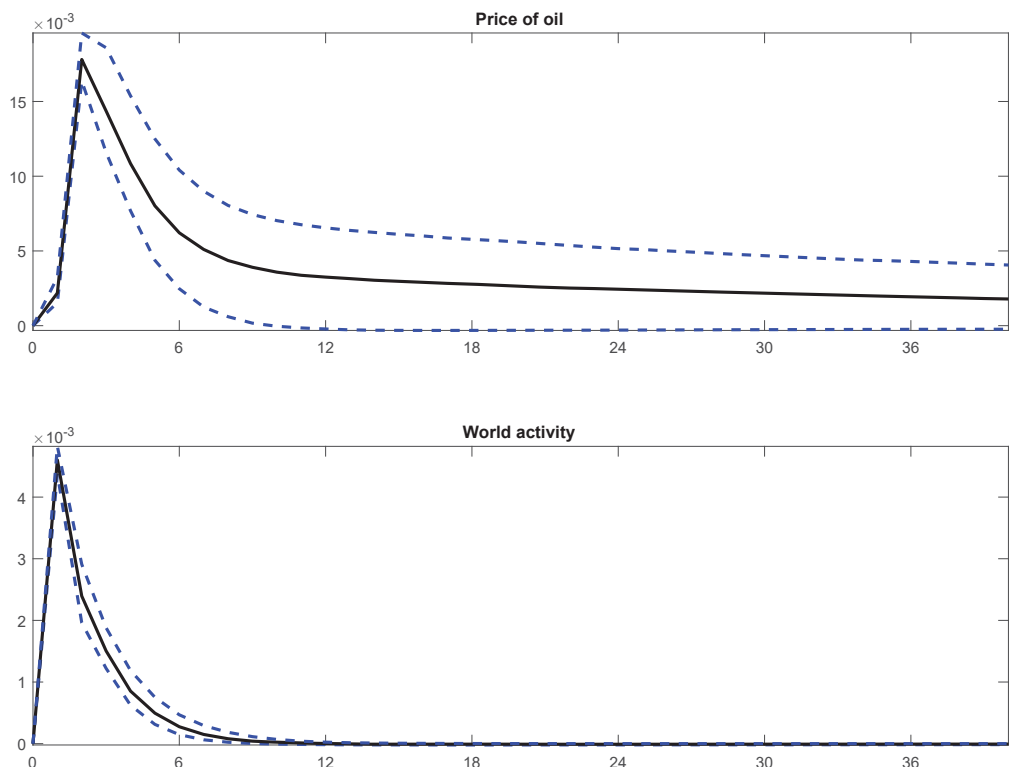

Figure 3: World demand shock

Note: The figure graphs the generalized impulse responses to a world demand shock (that is normalized to increase world activity)

literature on the Great Moderation, see e.g. Bianchi (2013) and Liu, Waggoner and Zha (2011). ${ }^{15}$ In addition, we identify some shorter periods of heightened volatility later in the sample, mostly coinciding with the NBER recessions of 2001/2002, also picked up by Liu, Waggoner and Zha (2011), and during the period of the recent great recession, which is picked up by most other studies.

The second row shows our main results, namely the smoothed probabilities for the high oil price volatility state. The figure suggests there is no support for the hypothesis that a fall in oil price volatility coincided with the decline in macroeconomic instability from the mid-1980s (the start of the Great Moderation) noted in many previous studies. Instead we find that the oil price has displayed several periods of heightened volatility throughout the sample, many of them coinciding with the NBER recessions. Thus, we do not find support for the hypothesis put forward in Nakov and Pescatori (2010) and Blanchard and Gali (2008), which, based on a split sample, find reduced oil price volatility to have contributed to reduce macroeconomic instability over time.

Looking at the graph in more detail, we identify 7 distinct periods where the structural shocks to the oil price are in a high volatility state. Interestingly, these episodes correspond well with the historical episodes identified as exogenous oil price shocks in Hamilton (2013). The first and second episodes are well-known distinct spurs of high oil price

\footnotetext{
${ }^{15}$ These results are also in line with findings in Herrera and Pesavento (2009). Using a structural VAR, they find two structural breaks in inventories and sales (thus production) for US industries; an increase in volatility around the 1970s and a drop in volatility in the mid-1980s.
} 

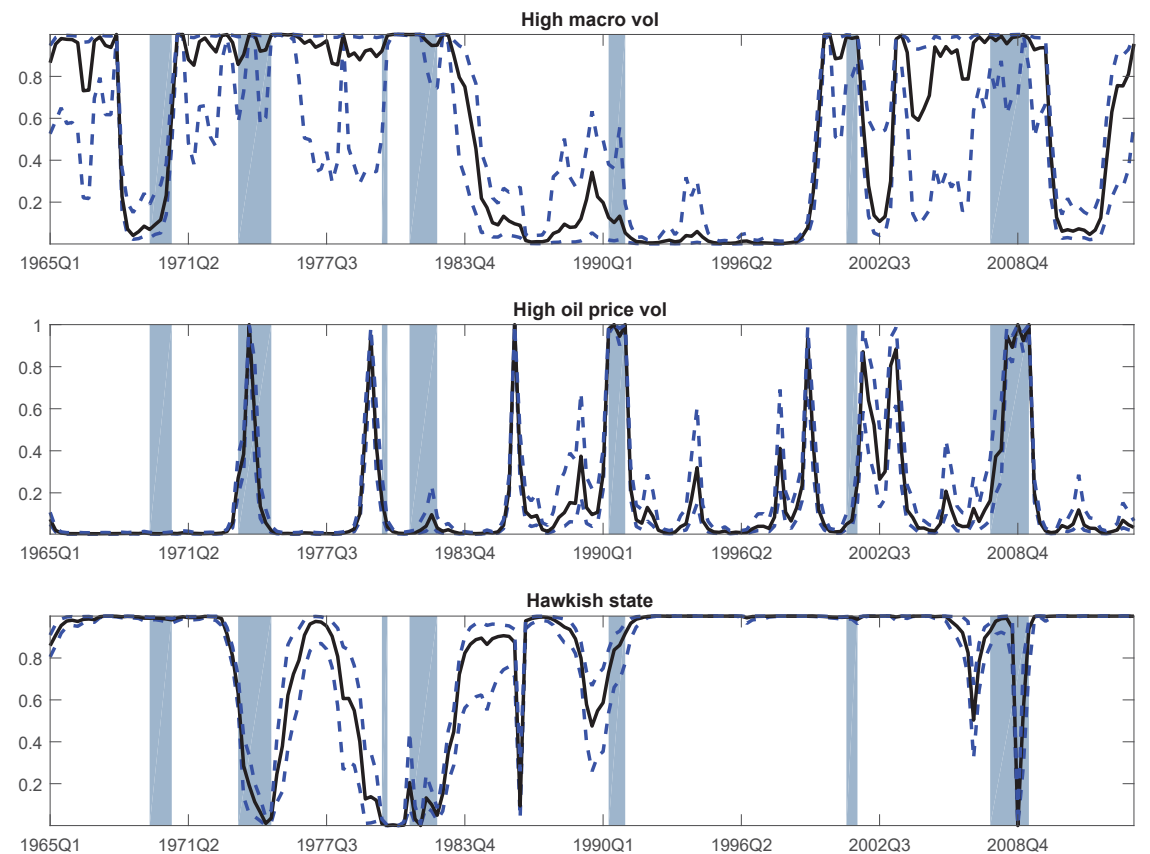

Figure 4: Historical state probabilities

Note: The top row presents the smoothed probabilities for being in the high macroeconomic volatility state. The second row presents the smoothed probabilities for being in the high oil price volatility state. The bottom row presents the smoothed probabilities for being in the high monetary policy response state. The figures graph the median response, together with the 68 percent probability bands. The shaded areas correspond to the dated NBER recessions.

volatility: the 1973-1974 OPEC embargo, and the 1978 Iranian revolution followed by the Iran-Iraq war of 1980. Both episodes led to a fall in world oil production, an increase in oil prices and a gasoline shortage in the U.S., see Hamilton (2013) for more details. ${ }^{16}$ Between 1981 and 1985, Saudi Arabia held production down to stimulate the price of oil until, in 1986, they brought production up again, which led in turn to a collapse in the oil price. This sharp fall in 1986 coincides with our third episode. The fourth episode in 1990/1991 coincides with the Persian Gulf war during which Iraqi production collapsed and oil prices shot up. The fifth period (1998-2000) coincides with the East Asian Crisis and the subsequent recovery. During this period the oil price first fell below $\$ 12$, the lowest price since 1972 , before it shot up again from $1999 / 2000$. The spike in 2002-2003 coincides with the Venezuelan unrest and the second Persian Gulf war and is our sixth episode. The seventh episode, 2007-2008, coincides with what Hamilton (2013) calls a period of growing demand and stagnant supply. The probability of a high oil price

\footnotetext{
${ }^{16}$ Note that Hamilton describes the end of the 1960 s as a period with modest price increases, in part a response to the broader inflationary pressures of the late 1960s. Consistent with this, we do not pick up any episodes in the 1960s of high oil price volatility in Figure 4.
} 
volatility state coincides with the last NBER recession.

Of the seven episodes of high oil price volatility identified here, all but two preceded the NBER dated recessions, suggesting high oil price volatility may have played a role here. The exceptions are the episode in 1986 when oil prices fell sharply, hence, if anything, we should have seen a period of boosted growth in the U.S., and the period 2002-2003, when the increase in oil prices turned out to be modest and short lived (see Hamilton (2013)).

We conclude that while all the NBER recessions since the 1970s have been associated with high oil price volatility, not all oil shocks led to a recession. Only when oil pries are both volatile and high, do they in particular coincide with recessions. We will return to the issue of the role of oil in the recession when examining impulse responses below.

The bottom panel shows the smoothed probabilities for the high monetary policy response state. There is a widespread belief that the more Hawkish policy imposed by Chair of the Federal Reserve Paul Volcker helped bring down the high inflation that persisted during the 1970s, see e.g. Clarida, Gali and Gertler (2000) and Lubik and Schorfheide (2004). Our results support this view that the Fed's response to inflation grew stronger after Volcker took office. ${ }^{17}$ However, we do not identify such a switch to a hawkish state to occur before 1982, which is approximately one year later than what e.g. Bianchi (2013) and Baele et al. (2015) found. We believe this to relate to the fact that it took some time for inflation to come down. The economy stays in the hawkish state thereafter, except for brief periods in the mid 2000s and during the financial crisis, when policy became more lax, i.e., the probability of being in the hawkish state declines rapidly. By the end of the sample, policy is again more hawkish.

To sum up, we do not find declining oil price volatility to play an independent role for the observed volatility reduction in the U.S. economy from the mid 1980s. Instead we find recurrent episodes of heightened oil price volatility throughout the sample, many of them preceding the NBER dated recessions. This is a new finding in the literature. Regarding the other macroeconomic shocks, we confirm Liu, Waggoner and Zha (2011) and Bianchi (2013), which find that the Great Moderation is mostly explained by a change in the volatility of exogenous macroeconomic shocks, although monetary policy nevertheless seems to have also played a role.

\subsection{Oil and the macroeconomy}

Having observed the coinciding pattern of heightened oil price volatility and the NBERdated U.S. recession, a natural follow-up question is how an oil price shock affects the macroeconomy? Figure 5 addresses this question by graphing the generalized impulse

\footnotetext{
${ }^{17}$ Paul Volcker was Chairman of the Federal Reserve under Presidents Jimmy Carter and Ronald Reagan from August 1979 to August 1987.
} 

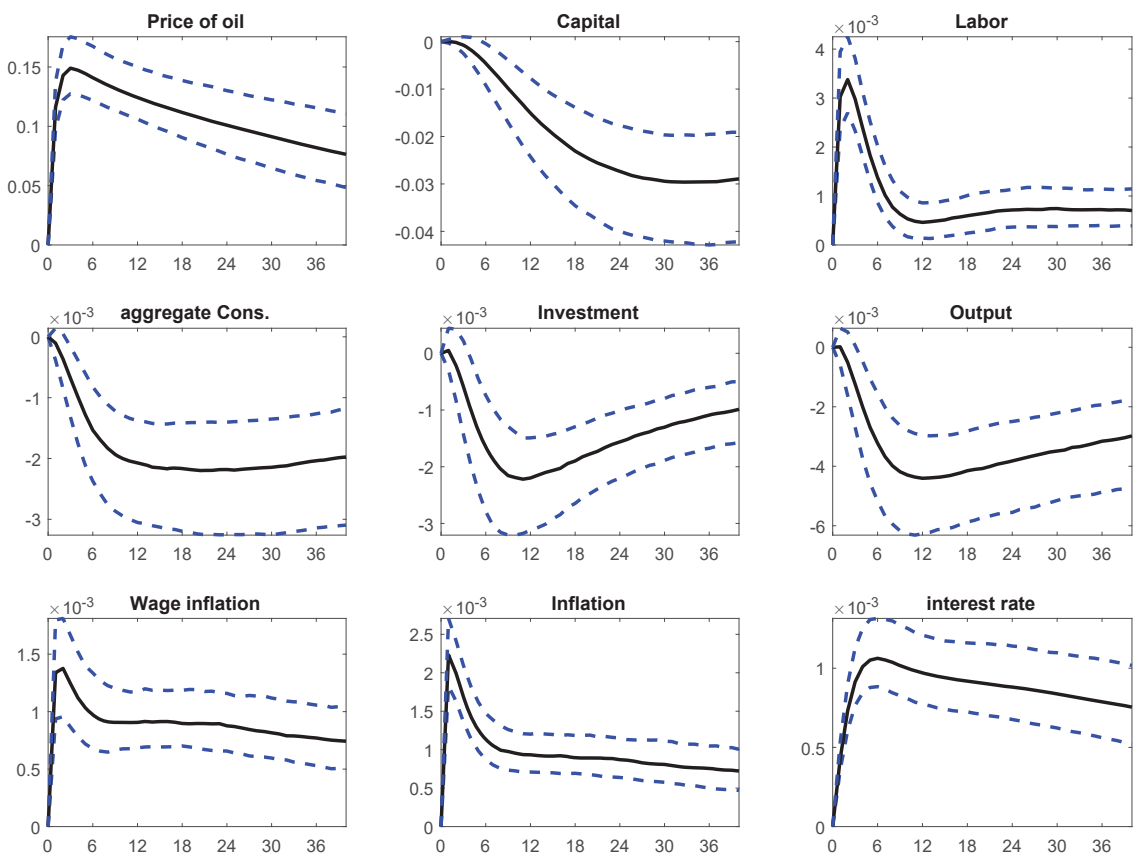

Figure 5: Impulse responses to an oil price shock

Note: The figure displays the generalized impulse responses to an oil price shock.

responses to an oil price shock with probability bands. The figure shows that following a standard deviation shock to oil price of approximately 15 percent, U.S. GDP declines gradually, by $0.4-0.5$ percent within two years, as the cost of production increases. This will lower profit and reduce capital accumulation and investment by firms, and eventually also consumption by households. With an increased cost of production, firms wish to substitute with labor, hence the use of labor increases, pushing up wage growth and inflation rapidly by $0.2-0.3$ percentage points. The latter motivates an increase in interest rates of 0.1 percentage point.

How do these results compare with previous studies analyzing the effects of an oil price shock? Regarding the size of the responses for GDP, our results are in line with structural VAR studies such as e.g. Hamilton (2003) and Hamilton and Herrera (2004), which find that a 10 percent (exogenous) increase in the oil price reduces GDP by roughly $0.4-0.8$ percent, depending on the sample and model specification. These studies, however, do not distinguish between the different sources of shocks as they implicitly assume that oil price changes exclusively originate from the supply side of the oil market. Controlling for global demand shocks, however, Kilian (2009) find much smaller effects. Yet, more recent studies such as Aastveit, Bjørnland and Thorsrud (2015) and Caldara, Cavallo and Iacoviello (2016) have shown that allowing for different responses across developed and emerging countries, the negative effects for developed countries will be stronger than what Kilian (2009) reported, more in line with what we find here. 
Table 2: Variance decomposition - contribution of oil price shocks

\begin{tabular}{cccccc} 
Variable $\backslash$ Horizon & & 1 & 4 & 8 & 20 \\
\hline GDP & Regime 7 & 0.06 & 0.70 & 1.20 & 1.20 \\
growth & Regime 5 & 0.82 & 8.50 & 13.00 & 14.00 \\
\hline CPI - & Regime 7 & 14.00 & 12.00 & 12.00 & 13.00 \\
inflation & Regime 5 & 68.00 & 65.00 & 63.00 & 67.00 \\
\hline Wage- & Regime 7 & 3.30 & 2.70 & 2.50 & 3.60 \\
inflation & Regime 5 & 31.00 & 27.00 & 26.00 & 33.00 \\
\hline Interest & Regime 7 & 1.00 & 5.90 & 10.00 & 15.00 \\
rate & Regime 5 & 12.00 & 45.00 & 61.00 & 70.00
\end{tabular}

Note: For each variable and horizon we display two numbers in the bracket: Top row, the variance explained when the economy is in Regime 7 (low oil price volatility, low macro volatility and hawkish policy) and bottom row, the variance explained when the economy is in Regime 5 (high oil price volatility, low macro volatility and hawkish policy). See the main text for more details.

Having examined the impulse responses, we need to also establish the role of the oil price shocks in explaining the variance in the variables over time. Table 2 summarizes the findings for four key variables: GDP growth, CPI inflation, wage inflation and interest rates. For each variable and horizon we display two numbers; in the top row, the variance explained by the oil price shocks when the economy is in a regime that has a high probability of occurrence, i.e., 'normal times' (Regime 7: low oil price volatility, low macro volatility and hawkish policy) and in the bottom row, the variance explained by the oil price shocks when the economy is in a regime where the oil price shocks have a large impact (Regime 5: high oil price volatility, low macro volatility and hawkish policy). We compare these two regimes to spell out some main differences. In the online appendix, we display variance decomposition and smoothed probabilities for all eight regimes.

We have three main findings. First, as can be seen from Table 2, the contribution of the oil price shocks are substantial when oil price volatility is high (bottom row), explaining 913 percent of GDP growth and around 65 percent of inflation after 1-2 years. In contrast, oil price shocks explain a modest 1 percent of GDP growth and 12 percent of inflation after 1-2 years in periods of 'normal times' (top row). Hence, our results clearly suggest that when analysing the role of oil price shocks in the economy, one needs to separate between periods when oil price volatility is high and periods when oil price volatility is low. Estimating the oil-macroeconomic relationship using a model with constant parameters, may lead one to underestimate the role of oil in the economy. Our results also suggest an independent role for oil price shocks in the past and present recessions, in line with the 

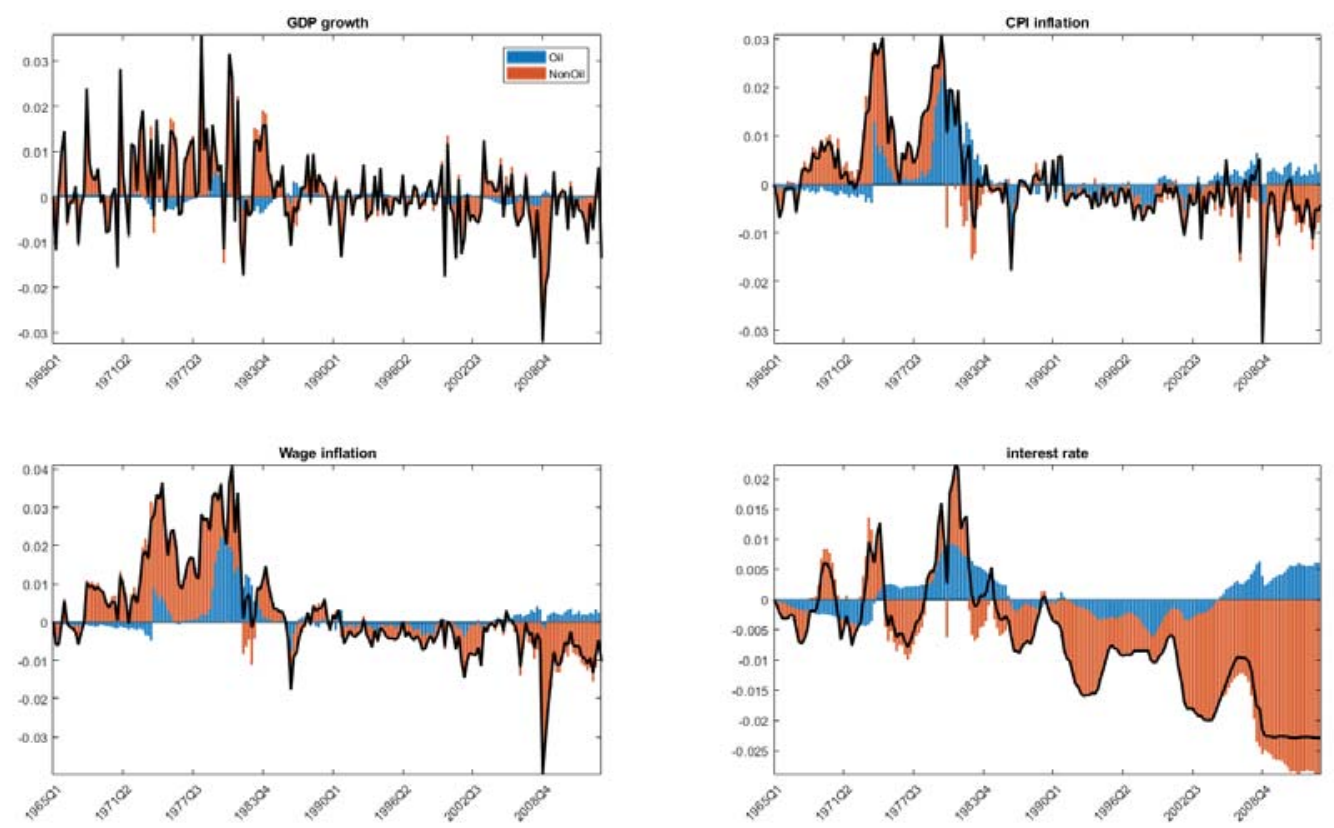

Figure 6: Historical decomposition

Note: The figure shows the historical contribution to some key variables of oil and non-oil shocks (grouped separately). In so doing, we abstract for the role of constants or initial conditions.

arguments put forward in Hamilton (2009).

Second, according to Bernanke, Gertler and Watson (1997), it is not the oil price shocks themselves that depress output over time, but the Federal Reserve's contractionary response to inflationary concerns. Had it not been for these responses, the economic downturns might have been largely avoided. ${ }^{18}$ We find little evidence for this. When oil price volatility is high, we find the effects on output (and inflation) to be substantial in any case. However, when oil price volatility is low, we do find that the negative effect on output of an oil price shock is magnified somewhat when the policymakers are in the high policy response (hawkish) regimes, while the variance in inflation is magnified in the dowish regimes. One reason is that the increase in interest rates in the contractionary phase, although effectively curbing inflation, will exacerbate the oil-led contraction of the economy. However, as it turns out, since the policymakers have been in the high response regime since the early 1980s, oil price shocks have been contractionary for the U.S. economy in the period of the Great Moderation (post 1983/1984), and not just in the Volcker area (1979-1987) as suggested in Bernanke, Gertler and Watson (1997), see the Tables 8 - 15 in Appendix E for further evidence.

\footnotetext{
${ }^{18}$ Note, however, that Hamilton and Herrera (2004) have a number of criticisms of this conclusion. In particular, Hamilton and Herrera (2004) show that (i) the effect of systematic monetary policy found in Bernanke, Gertler and Watson (1997) is overestimated relative to a model that includes more lags and (ii) the counterfactual scenario is not feasible in the sense that the shocks needed to keep the federal funds rate unchanged would hardly constitute surprises.
} 
Third, although oil price shocks explain a smaller share of the variance in inflation in the hawkish than the dowish regime, there is still a substantial share explained by the oil price shocks when oil price volatility is high (see Table 2). This suggests that during periods of high oil price volatility, stabilizing inflation is difficult.

Figure 6 provides further information, but now by examining the historical decomposition of the four key variables due to the oil shocks and the non-oil shocks (grouped) separately in each point in time. The figure shows clearly that oil price shocks matter in specific periods. There is a negative contribution to GDP when oil price volatility is high in the mid and late 1970s, in the early 1990s and the periods preceding the financial crisis. For wage and CPI inflation, however, the contribution is even more severe. Throughout the 1970s, the oil price shocks contributed to both high wage and CPI inflation, and eventually also higher interest rates. But also by the end of the sample, oil prices contributed to higher inflation. In fact, if it hadn't been for the contribution of the oil price shocks, the rise in CPI inflation (and interest rates) would have been even lower.

\section{Robustness}

We began this paper by questioning whether a reduction in oil price volatility could be partly responsible for the period of stable economic conditions from the mid-1980s known as the Great Moderation. Our results suggest that, contrary to common perception, there is no support for the role of oil price shocks in reducing macroeconomic instability. Instead, periods of heightened oil price volatility are a recurrent feature of our sample.

One concern with the analysis conducted so far, could be that even a model allowing for high and low volatility of the oil shocks may be too rigid. It is apparent that the first oil shock (in 1973/1974) was larger in size than any other subsequent increase. Second, this shock was unprecedented. In other words, oil prices experienced a large increase for the first time in economic history. Maybe our results for the high oil price volatility regime are too heavily influenced by this one event? To analyze this, we redo the analysis starting the estimation in 1975 instead, effectively removing the influence of the first OPEC shock. Results reported in the online appendix shows that the results are robust to this change.

We also examine if our result could be biased due to the prolonged episode of zero lower bound after the financial crisis. To do so we stop the estimation in 2008. Results are also robust to this change, see the online appendix. 


\section{Conclusion}

This paper revisits the role of oil price volatility in reducing macroeconomic volatility by estimating Markov Switching Rational Expectation New-Keynesian models that accommodate regime-switching behavior in shocks to oil prices, macro variables as well as in monetary policy. With the structural model we revisit the timing of the Great Moderation (if any) and the sources of changes in the volatility of macroeconomic variables.

We have three major findings. First, our results support regime switching in monetary policy, U.S. shock volatility and oil price shock volatility. In particular, to fully understand the role of oil in the macroeconomy, it is important to separate between periods of low and high oil price volatility.

Second, we do not find a break in oil price volatility from the mid-1980s that coincides with the Great Moderation. We find instead several short periods of heightened oil price volatility throughout the whole sample, many of them preceding the dated NBER recession. If anything, the post-1984 period has had more episodes of high volatility than the pre-1984 period. Hence, according to our results, we cannot argue that declining oil price volatility was a factor in the reduced volatility of other U.S. macroeconomic variables. Instead, and in contrast to common perceptions, we confirm the relevance of oil as a recurrent source of macroeconomic fluctuations.

Third, the most important factor reducing macroeconomic variability is the decline in the volatility of structural macroeconomic shocks. The break date is estimated to occur in 1984/1985. That is not to say there has not been any surges of volatility since then. However, these periods of heightened macroeconomic volatility have been briefer, maybe because a more credible monetary policy regime has also been in place since 1982/1983, responding more strongly to inflation.

Thus, if indeed the recurrent spikes in oil prices are causal factors contributing to economic downturns, the Federal Reserve should give careful consideration to the possible consequences of shocks to commodity prices when designing monetary policy.

\section{References}

Aastveit, Knut Are, Hilde C. Bjørnland, and Leif Anders Thorsrud. 2015. "What drives oil prices? Emerging versus developed economies." Journal of Applied Econometrics, 30(7): 1013-28.

Baele, Lieven, Geert Bekaert, Seonghoon Cho, Koen Inghelbrecht, and Antonio Moreno. 2015. "Macroeconomic regimes." Journal of Monetary Economics, 70: $51-71$. 
Bernanke, Ben S., Mark Gertler, and Mark Watson. 1997. "Systematic Monetary Policy and the Effects of Oil Price Shocks." Brookings Papers on Economic Activity, 1997(1): pp. 91-142.

Bianchi, Francesco. 2013. "Regime Switches, Agents' Beliefs, and Post-World War II US Macroeconomic Dynamics." The Review of Economic Studies, 80(2): 463-490.

Bikbov, Ruslan, and Mikhail Chernov. 2013. "Monetary policy regimes and the term structure of interest rates." Journal of Econometrics, 174: 27-43.

Bjørnland, Hilde C. 2000. "The Dynamic Effects of Aggregate Demand, Supply and Oil Price Shocks - A Comparative Study." Manchester School, 68(5): 578-607.

Bjørnland, Hilde C., and Leif A. Thorsrud. 2016. "Boom or Gloom? Examining the Dutch Disease in Two-speed Economies." The Economic Journal, 126(598): 2219-2256.

Blanchard, Olivier J, and Jordi Gali. 2008. "The Macroeconomic Effects of Oil Shocks: Why are the 2000s so different from the 1970s?" National Bureau of Economic Research NBER Working Papers 13368.

Burbidge, John, and Alan Harrison. 1984. "Testing for the Effects of Oil-Price Rises Using Vector Autoregressions." International Economic Review, 25(2): 459-84.

Caldara, Dario, Michele Cavallo, and Matteo Iacoviello. 2016. "Oil Price Elasticities and Oil Price Fluctuations." Mimeo, Federal Reserve Board.

Canova, Fabio, Luca Gambetti, and Evi Pappa. 2007. "The Structural Dynamics of Output Growth and Inflation: Some International Evidence." The Economic Journal, 117(519): C167-C191.

Charnavoki, Valery, and Juan Dolado. 2014. "The Effects of Global Shocks on Small Commodity-Exporting Economies: Lessons from Canada." American Economic Journal: Macroeconomics, 6(2): 207-237.

Cho, Seonghoon. 2014. "Characterizing Markov-Switching Rational Expectation Models." Yonsei University Working Paper.

Christiano, Lawrence J, Martin Eichenbaum, and Charles L Evans. 2005. "Nominal rigidities and the dynamic effects of a shock to monetary policy." Journal of Political Economy, 113(1): 1-45.

Clarida, Richard, Jordi Gali, and Mark Gertler. 2000. "Monetary policy rules and macroeconomic stability: Evidence and some theory." The Quarterly Journal of Economics, 115(1): 147-180. 
Costa, Oswaldo Luiz Do Valle, Marcelo Dutra Fragoso, and Ricardo Paulino Marques. 2005. Discrete-Time Markov Jump Linear Systems. Springer.

Farmer, Roger EA, Daniel F Waggoner, and Tao Zha. 2011. "Minimal state variable solutions to Markov-switching rational expectations models." Journal of Economic Dynamics and Control, 35(12): 2150-2166.

Gelman, Andrew, John B. Carlin, Hal S. Stern, and Donald B. Rubin. 2004. Bayesian Data Analysis. . 2 ed., Chapman \& Hall/CRC.

Gisser, Micha, and Thomas H Goodwin. 1986. "Crude Oil and the Macroeconomy: Tests of Some Popular Notions: A Note." Journal of Money, Credit and Banking, 18(1): 95-103.

Gupta, Vijay, Richard Murray, and Babak Hassibi. 2003. "On the Control of Jump Linear Markov Systems with Markov State Estimation." 2893-2898.

Hamilton, James D. 1983. "Oil and the Macroeconomy since World War II." Journal of Political Economy, 91(2): 228-48.

Hamilton, James D. 1996. "This is what happened to the oil price-macroeconomy relationship." Journal of Monetary Economics, 38(2): 215-220.

Hamilton, James D. 2003. "What is an oil shock?" Journal of Econometrics, 113(2): 363-398.

Hamilton, James D. 2009. "Causes and Consequences of the Oil Shock of 2007-08." Brookings Papers on Economic Activity, 40(1): 215-283.

Hamilton, James D. 2013. "Historical Oil Shocks." In Routledge Handbook of Major Events in Economic History. , ed. Randall E. Parker and Robert M. Whaples, 239-265. New York: Routledge Taylor and Francis Group.

Hamilton, James D, and Ana Maria Herrera. 2004. "Oil Shocks and Aggregate Macroeconomic Behavior: The Role of Monetary Policy: Comment." Journal of Money, Credit and Banking, 36(2): 265-86.

Herrera, Ana María, and Elena Pesavento. 2009. "Oil price shocks, systematic monetary policy, and the great moderation?" Macroeconomic Dynamics, 13(01): 107137.

Kilian, Lutz. 2009. "Not All Oil Price Shocks Are Alike: Disentangling Demand and Supply Shocks in the Crude Oil Market." American Economic Review, 99(3): 1053-69. 
Kim, Chang-Jin, and Charles R Nelson. 1999a. "Has the US economy become more stable? A Bayesian approach based on a Markov-switching model of the business cycle." Review of Economics and Statistics, 81(4): 608-616.

Kim, Chang-Jin, and Charles R. Nelson. 1999b. State-Space Models with Regime Switching: Classical and Gibbs-Sampling Approaches with Applications. Vol. 1. 1 ed., The MIT Press.

Lippi, Francesco, and Andrea Nobili. 2012. "Oil And The Macroeconomy: A Quantitative Structural Analysis." Journal of the European Economic Association, 10(5): 1059-1083.

Liu, Zheng, Daniel F Waggoner, and Tao Zha. 2011. "Sources of macroeconomic fluctuations: A regime-switching DSGE approach." Quantitative Economics, 2(2): 251301.

Lubik, Thomas A, and Frank Schorfheide. 2004. "Testing for indeterminacy: an application to US monetary policy." American Economic Review, 94(1): 190-217.

Maih, Junior. 2014. "Efficient perturbation methods for solving regime-switching DSGE models." CAMP Working Paper Series 10/2014.

McConnell, Margaret M, and Gabriel Perez-Quiros. 2000. "Output fluctuations in the United States: What has changed since the early 1980's?" American Economic Review, 90: 1464-1476.

Nakov, Anton, and Andrea Pescatori. 2010. "Oil and the Great Moderation." Economic Journal, 120(543): 131-156.

Peersman, Gert, and Ine Van Robays. 2012. "Cross-Country Differences in the Effects of Oil Shocks." Energy Economics, 34(5): 1532-1547.

Sims, Christopher A. 2002. "Solving linear rational expectations models." Computational Economics, 20(1): 1-20.

Sims, Christopher A., and Tao Zha. 2006. "Where there regime switches in U.S. monetary policy?" American Economic Review, 96(1): 54-81.

Smets, Frank, and Rafael Wouters. 2007. "Shocks and frictions in US business cycles: A Bayesian DSGE approach." The American Economic Review, 97(3): 586-606.

Stock, James H, and Mark W Watson. 2003. "Has the business cycle changed and why?" In NBER Macroeconomics Annual 2002, Volume 17. 159-230. MIT press. 
Svensson, Lars E. O., and Noah Williams. 2007. "Monetary Policy with Model Uncertainty: Distribution Forecast Targeting." C.E.P.R. CEPR Discussion Papers 6331. 


\section{A Data and transformations}

The model is is estimated using quarterly data from the period 1965Q1-2014Q1. We have 8 observables in the system. We list all the observables together with the variable name used in the model and the corresponding equations (measurement equations) in Appendix B.1: the federal funds rate ( $r$, Eq. 48), world GDP growth $\left(\Delta G D P_{t}^{W}\right.$, Eq. 49), GDP growth $(\triangle G D P$, Eq. 50), investment growth $(\Delta I N V$, Eq. 51), consumption growth $(\triangle C O N S$, Eq. 52), wage inflation ( $\triangle W A G E S$, Eq. 53), CPI-based inflation $(\triangle C P I$, Eq. 54) and oil price inflation $\left(\Delta P^{\mathrm{OIL}}\right.$, Eq. 55).

All the series with the exception of the growth rate of world activity were downloaded from the FRED database. ${ }^{19}$ We calculate real per capita values for GDP, consumption and investment. For world activity we use quarterly GDP growth (percentage change) for the OECD countries. The series is named OECD - total and is downloaded from OECD. ${ }^{20}$

\section{B Model derivations}

\section{THE HOUSEHOLD PROBLEM}

Households maximize utility subject to a budget constraint and the law of motion for capital. The Lagrangian for the household problem is given by

$$
\begin{aligned}
\mathcal{L}_{H H} & =\mathbb{E}_{0} \sum_{t=0}^{\infty} \beta^{t}\left\{z_{t}\left[\frac{\left(\frac{C_{t}-\chi C_{t-1}}{A_{t}^{C}}\right)^{1-\sigma}}{1-\sigma}-\kappa_{t} \frac{n_{t}^{1+\vartheta}}{1+\vartheta}\right]\right. \\
& -\Lambda_{t}\left(P_{t} C_{t}+P_{t} I_{K, t}+D_{t-1} r_{t-1}+P_{t} T_{t}+F_{t}-W_{t} n_{t}-R_{K, t} K_{t-1}-D_{t}-D I V_{t}\right) \\
& \left.-\Lambda_{t} Q_{K, t}\left(K_{t}-(1-\delta) K_{t-1}-\left[1-\frac{\phi_{k}}{2}\left(\frac{I_{K, t}}{I_{K, t-1}}-\exp \left(g_{i k}\right)\right)^{2}\right] I_{K, t} A_{t}^{I K}\right)\right\},
\end{aligned}
$$

where $\beta \in(0,1)$ is the subjective discount factor, $\sigma>0$ is the intertemporal elasticity of substitution, $\vartheta$ is the inverse of the Frish elasticity, $\delta \in(0,1)$ is the depreciation rate of capital, $\phi_{k}$ governs the degree of investment adjustment costs, and $g_{i k}$ is the growth rate

\footnotetext{
${ }^{19}$ See http://research.stlouisfed.org/fred2/. In the FRED database, the nominal GDP series is denoted $g d p$, the GDP deflator is named $g d p d e f$, the federal funds rate is named fedfunds, the WTI series is named dcoilwtico, investments is named gpdi, wages is named pcec, consumption is named pcec, the labor force is named clf16ov and the CPI is named cpiaucsl.

${ }^{20}$ www . data. oecd.org
} 
of investment. The first order conditions:

$$
\begin{aligned}
C_{t}: & z_{t}\left(C_{t}-\chi C_{t-1}\right)^{-\sigma}\left(A_{t}^{C}\right)^{\sigma-1}=\Lambda_{t} P_{t} \\
D_{t}: & \Lambda_{t}=\beta \mathbb{E}_{t}\left[\Lambda_{t+1} r_{t}\right] \\
K_{t}: & \Lambda_{t} Q_{K, t}=\mathbb{E}_{t}\left[\beta \Lambda_{t+1}\left(R_{K, t+1}+Q_{K, t+1}(1-\delta)\right)\right] \\
I_{K, t}: & \Lambda_{t} P_{t}=\Lambda_{t} Q_{K, t} A_{t}^{I K}\left[1-\frac{\phi_{k}}{2}\left(\frac{I_{K, t}}{I_{K, t-1}}-\exp \left(g_{i k}\right)\right)^{2}-\phi_{k}\left(\frac{I_{K, t}}{I_{K, t-1}}-\exp \left(g_{i k}\right)\right) \frac{I_{K, t}}{I_{K, t-1}}\right] \\
& \quad+\mathbb{E}_{t}\left[\phi_{k} \beta \Lambda_{t+1} Q_{K, t+1} A_{t+1}^{I K}\left(\frac{I_{K, t+1}}{I_{K, t}}-\exp \left(g_{i k}\right)\right)\left(\frac{I_{K, t+1}}{I_{K, t}}\right)^{2}\right] .
\end{aligned}
$$

The first order condition for $C_{t}$ gives Equation 26, $K_{t}$ gives Equation 29, and $I_{K, t}$ gives Equation 30. We also define the stochastic discount factor as

$$
m_{t} \equiv \mathbb{E}_{t}\left\{\beta \frac{\Lambda_{t+1}}{\Lambda_{t}}\right\}
$$

and together with the first order condition w.r.t. $D_{t}$, we get Equation 27 and 28.

\section{Optimal WAge SETting A LA Rotemberg}

Wages are chosen by minimizing household disutility of working subject to the budget constraint and a quadratic cost of adjusting wages. Wage inflation is defined as

$$
\pi_{t}^{w}=\frac{W_{t}}{W_{t-1}}
$$

We assume wage indexation given by

$$
\ddot{\pi}_{t}^{w} \equiv\left(\pi_{t-1}^{w}\right)^{\gamma_{w}}\left(\bar{\pi}^{w}\right)^{1-\gamma_{w}} .
$$

The Lagrangian for the labor unions:

$$
\begin{aligned}
\mathcal{L}_{W S} & =\mathbb{E}_{0} \sum_{t=0}^{\infty} \beta^{t}\left\{z_{t} \kappa_{t}\left[-\frac{\left(\left(\frac{W_{j, t}}{W_{t}}\right)^{-v} n_{t}\right)^{1+\vartheta}}{1+\vartheta}\right]\right. \\
& -\zeta_{t}\left[P_{t} C_{t}+P_{t} I_{K, t}-D_{t}-W_{j, t}\left(\frac{W_{j, t}}{W_{t}}\right)^{-v} n_{t}-R_{K, t} K_{t-1}+D_{t-1} r_{t-1}\right. \\
& \left.\left.+P_{t} T A X_{t}+\frac{\xi}{2}\left[\frac{W_{j, t}}{W_{j, t-1}}-\ddot{\pi}_{t}^{w}\right]^{2} W_{t} n_{t}-D I V_{t}\right]\right\},
\end{aligned}
$$


where $v$ is the elasticity of substitution between different types of labor, and $\xi$ governs the degree of cost of changing wages. First order conditions w.r.t. $W_{j, t}$ :

$$
\begin{aligned}
0= & v z_{t} \kappa_{t} \frac{n_{t}}{W_{t}}\left(\left(\frac{W_{j, t}}{W_{t}}\right)^{-v} n_{t}\right)^{\vartheta}\left(\frac{W_{j, t}}{W_{t}}\right)^{-v-1}+\zeta_{t}(1-v) W_{j, t}^{-v} W_{t}^{v} n_{t} \\
& -\Lambda_{t} \xi\left[\frac{W_{j, t}}{W_{j, t-1}}-\ddot{\pi} w\right] \frac{W_{t} n_{t}}{W_{j, t-1}}+\mathbb{E}_{t}\left\{\beta \Lambda_{t+1} \xi W_{t+1} n_{t+1} \frac{W_{j, t+1}}{W_{j, t}^{2}}\left[\frac{W_{j, t+1}}{W_{j, t}}-\ddot{\pi}_{t}^{w}\right]\right\} \\
= & v z_{t} \kappa_{t} \frac{n_{j, t}^{1+\vartheta}}{W_{j, t}}+\Lambda_{t}(1-v) n_{j, t} \\
& -\Lambda_{t} \xi \frac{W_{t} n_{t}}{W_{j, t-1}}\left[\frac{W_{j, t}}{W_{j, t-1}}-\ddot{\pi}_{t}^{w}\right]+\mathbb{E}_{t}\left\{\beta \Lambda_{t+1} \xi W_{t+1} n_{t+1} \frac{W_{j, t+1}}{W_{j, t}^{2}}\left[\frac{W_{j, t+1}}{W_{j, t}}-\ddot{\pi}_{t}^{w}\right]\right\} .
\end{aligned}
$$

Invoking symmetry and dividing throughout by $\Lambda_{t}(v-1) n_{t}$ :

$$
\begin{aligned}
0= & \frac{v}{v-1} z_{t} \kappa_{t} \frac{n_{t}^{\vartheta}}{\Lambda_{t} W_{t}}-1 \\
& -\frac{\xi}{v-1} \frac{W_{t}}{W_{t-1}}\left[\frac{W_{t}}{W_{t-1}}-\ddot{\pi}_{t}^{w}\right]+\mathbb{E}_{t}\left\{\beta \frac{\Lambda_{t+1}}{\Lambda_{t}} \frac{\xi}{v-1} \frac{n_{t+1}}{n_{t}}\left(\frac{W_{t+1}}{W_{t}}\right)^{2}\left[\frac{W_{t+1}}{W_{t}}-\ddot{\pi}_{t}^{w}\right]\right\},
\end{aligned}
$$

which gives Equation 47.

\section{INTERMEDIATE GOODS FIRMS' PROBLEM}

Firms have the following technology

$$
Y_{i t}=A_{t}\left[O_{i, t}^{\varrho} K_{i, t-1}^{1-\varrho}\right]^{\alpha} n_{i, t}^{1-\alpha},
$$

and maximize profits given by

$$
D I V_{i, t}=P_{i, t} Y_{i, t}-W_{i, t} n_{i, t}-R_{K, t} K_{i, t-1}-P_{O, t} O_{i, t}+F_{i, t} .
$$

The firm solves

$$
\max _{n_{i, t}, K_{i, t-1}, O_{i, t}} \mathbb{E}_{0} \sum_{t=0}^{\infty} P_{i, t}\left[A_{t}\left[O_{i, t}^{\varrho} K_{i, t-1}^{1-\varrho}\right]^{\alpha} n_{i, t}^{1-\alpha}\right]-W_{i, t} n_{i, t}-R_{K, t} K_{i, t-1}-P_{o, t} O_{i, t}+F_{i, t},
$$

where $\alpha$, is the share of the oil and capital mix in production and $\varrho$ governs the mix of oil and capital. First order condition w.r.t. $P_{j, t}$ :

$$
\begin{aligned}
O_{i, t}: & \alpha \varrho \frac{\Psi_{i, t} Y_{i, t}}{O_{i, t}}=P_{o, t} \\
n_{i, t}: & (1-\alpha) \frac{\Psi_{i, t} Y_{i, t}}{n_{i, t}}=W_{i, t} \\
K_{i, t-1}: & \alpha(1-\varrho) \frac{\Psi_{i, t} Y_{i, t}}{K_{i, t-1}}=R_{K, t},
\end{aligned}
$$


where $\Psi_{i, t}$ is the inverse of the Lagrange multiplier, and can be interpreted as the firms' marginal cost. If we invoke symmetry, the first order condition for $O_{i, t}$ gives Equation 37, $n_{i, t}$ gives Equation 39, and $K_{i, t-1}$ gives Equation 38.

\section{Optimal PRICE SETTING A LA RotemberG}

Firms set prices to maximize revenue, $P_{i, t} Y_{i, t}$, minus cost of producing, $\Psi_{t} Y_{i, t}$, minus the cost of adjusting the price, $\frac{\omega}{2} P_{t} Y_{t}\left(\frac{P_{i, t}}{P_{i, t-1}}-\ddot{\pi}_{t}\right)^{2}$. Inflation is given by

$$
\pi_{t}=\frac{P_{t}}{P_{t-1}}
$$

and we have price indexation to the previous period

$$
\ddot{\pi}_{t} \equiv \pi_{t-1}^{\gamma_{\pi}} \bar{\pi}^{1-\gamma_{\pi}}
$$

We also include a shock to the value of production, called a stochastic subsidy shock $\varepsilon_{\pi, t}$. The firm problem is given by:

$$
\max _{P_{i, t}} \mathbb{E}_{t} \sum_{t=0}^{\infty} m_{t}\left[P_{i, t}\left(\frac{P_{i, t}}{P_{t}}\right)^{-\epsilon} Y_{t} \exp \left(\sigma_{\pi} \varepsilon_{\pi, t}\right)-\Psi_{t}\left(\frac{P_{i, t}}{P_{t}}\right)^{-\epsilon} Y_{t}-\frac{\omega}{2} P_{t} Y_{t}\left(\frac{P_{i, t}}{P_{i, t-1}}-\ddot{\pi}_{t}\right)^{2}\right]
$$

where $\epsilon$ is the elasticity of substitution between different varieties of goods, and $\omega$ governs the cost of adjusting prices. First order condition:

$$
\begin{aligned}
P_{i, t}: \quad 0 & =(1-\epsilon) Y_{i, t} \exp \left(\sigma_{\pi} \epsilon_{\pi, t}\right)+\epsilon \Psi_{t} \frac{Y_{t}}{P_{i, t}}-\omega \frac{P_{t}}{P_{i, t-1}} Y_{t}\left[\frac{P_{i, t}}{P_{i, t-1}}-\ddot{\pi}_{t}\right] \\
& +\mathbb{E}_{t}\left\{\omega m_{t+1} P_{t+1} Y_{t+1} \frac{P_{i, t+1}}{P_{i, t}^{2}}\left[\frac{P_{i, t+1}}{P_{i, t}}-\ddot{\pi}_{t+1}\right]\right\} .
\end{aligned}
$$

Invoking symmetry and dividing throughout by $(\epsilon-1) Y_{t}$ :

$$
\begin{aligned}
0 & =-\exp \left(\sigma_{\pi} \varepsilon_{\pi, t}\right)+\frac{\epsilon}{\epsilon-1} \frac{\Psi_{t}}{P_{t}}-\frac{\omega}{\epsilon-1} \frac{P_{t}}{P_{t-1}}\left[\frac{P_{t}}{P_{t-1}}-\ddot{\pi}_{t}\right] \\
& +\mathbb{E}_{t}\left\{\frac{\omega}{\epsilon-1} m_{t+1} \frac{Y_{t+1}}{Y_{t}}\left(\frac{P_{t+1}}{P_{t}}\right)\left[\frac{P_{t+1}}{P_{t}}-\ddot{\pi}_{t+1}\right]\right\},
\end{aligned}
$$

which gives Equation 40.

\section{AgGregation AND MARKET CLEARING}

The market for goods clear,

$$
Y_{t}=C_{t}+I_{K, t}+G_{t}
$$

Firm profits is given by

$$
D I V_{t}=P_{t} Y_{t}-W_{t} n_{t}-R_{K, t} K_{t-1}-P_{o, t} O_{t}+F_{t},
$$

which gives Equation 45. 


\section{B.1 The stationary system}

To get a stationary system we use the following variable transformations:

$c_{t} \equiv \frac{C_{t}}{A_{t}^{C}}, \lambda_{t} \equiv A_{t}^{C} \Lambda_{t} P_{t}, \mu_{a, t} \equiv \frac{A_{t}}{A_{t-1}}, \mu_{a c, t} \equiv \frac{A_{t}^{C}}{A_{t-1}^{C}}, \mu_{a i k, t} \equiv \frac{A_{t}^{I K}}{A_{t-1}^{I K}}, i_{k, t} \equiv \frac{I_{K, t}}{A_{t}^{C}}, f_{t} \equiv \frac{F_{t}}{A_{t}^{C} P_{t}}$,

$g_{t}=\frac{G_{t}}{A_{t}^{C}}, \operatorname{tax}_{t} \equiv \frac{T A X_{t}}{A_{t}^{C}}, w_{t}=\frac{W_{t}}{A_{t}^{C} P_{t}}, k_{t} \equiv \frac{K_{t}}{A_{t}^{C} A_{t}^{I K}}, r_{k, t} \equiv \frac{R_{K, t} A_{t}^{I K}}{P_{t}}, d_{t} \equiv \frac{D_{t}}{A_{t}^{C} P_{t}}, d i v_{t} \equiv \frac{D I V_{t}}{A_{t}^{C} P_{t}}$,

$q_{k, t} \equiv \frac{A_{t}^{I K} Q_{t}^{K}}{P_{t}}, y_{t} \equiv \frac{Y_{t}}{A_{t}^{C}}, \psi_{t} \equiv \frac{\Psi_{t}}{P_{t}}, o_{t} \equiv \frac{O_{t}}{A_{t}^{C} A_{t}^{I K}}, p_{o, t} \equiv \frac{P_{o, t} A_{t}^{I K}}{P_{t}}$

With these definitions the stationary system, corresponding to the set of equations coded up in the RISE toolbox, is as follows:

The labor preference shock process is given by

$$
\kappa_{t}=\kappa_{t-1}^{\rho_{\kappa}} \kappa^{1-\rho_{\kappa}} \exp \left(\sigma_{\kappa} \varepsilon_{\kappa, t}\right) .
$$

The intertemporal preference shock process is given by

$$
\log \left(z_{t}\right)=\rho_{z} \log \left(z_{t-1}\right)+\sigma_{z} \varepsilon_{z, t}
$$

The households have the following budget constraint

$$
c_{t}+i_{k, t}+\frac{d_{t-1} r_{t-1}}{\mu_{a c, t} \pi_{t}}+\operatorname{tax}_{t}+f_{t}=w_{t} n_{t}+\frac{r_{k, t} k_{t-1}}{\mu_{a i k, t} \mu_{a c, t}}+d_{t}+\operatorname{div}_{t} .
$$

Capital accumulation with capital adjustment costs

$$
k_{t}=\frac{(1-\delta) k_{t-1}}{\mu_{a c, t} \mu_{a i k, t}}+\left(1-\frac{\phi_{k}}{2}\left(\frac{\mu_{a c, t} i_{k, t}}{i_{k, t-1}}-\exp \left(g_{i k}\right)\right)^{2} i_{k, t}\right) .
$$

The capital investment shock process

$$
\mu_{a i k, t}=\exp \left(g_{a i k}+\sigma_{a i k} \varepsilon_{a i k, t}\right)
$$

Household FOCs give optimal allocation of consumption between periods

$$
z_{t}\left(c_{t}-\frac{\chi c_{t-1}}{\mu_{a c, t}}\right)^{-\sigma}=\lambda_{t}
$$

The pricing kernel is determined by the growth in marginal utility, and the stochastic discount factor is given by,

$$
m_{t}=\mathbb{E}_{t}\left[\frac{\beta \lambda_{t+1}}{\lambda_{t} \mu_{a c, t+1} \pi_{t+1}}\right]
$$

The stochastic discount factor is equal to the inverse of the interest rate

$$
m_{t}=\frac{1}{r_{t}}
$$

Optimal capital allocation is governed by

$$
\lambda_{t} q_{k, t}=\mathbb{E}_{t}\left\{\frac{\beta \lambda_{t+1}}{\mu_{a c, t+1} \mu_{a i k, t+1}}\left(r_{k, t+1}+q_{k, t+1}(1-\delta)\right)\right\} .
$$


The optimal level of investment is governed by

$$
\begin{aligned}
& \lambda_{t}=\lambda_{t} q_{k, t}\left(1-\frac{\phi_{k}}{2}\left(\frac{\mu_{a c, t} i_{k, t}}{i_{k, t-1}}-\exp \left(g_{i k}\right)\right)^{2}\right) \\
& -\lambda_{t} q_{k, t} \phi_{k}\left(\frac{\mu_{a c, t} i_{k, t}}{i_{k, t-1}}-\exp \left(g_{i k}\right)\right)\left(\frac{\mu_{a c, t} i_{k, t}}{i_{k, t-1}}\right) \\
& +\mathbb{E}_{t}\left\{\phi_{k} \beta \lambda_{t+1} q_{k, t+1}\left(\frac{\mu_{a c, t+1} i_{k, t+1}}{i_{k, t}}-\exp \left(g_{i k}\right)\right)\left(\frac{\mu_{a c, t+1} i_{k, t+1}}{i_{k, t}}\right)^{2}\right\}
\end{aligned}
$$

Membership fee to labor unions

$$
f_{t}=\frac{\xi}{2} w_{t} n_{t}\left(\pi_{t}^{w}-\ddot{\pi}_{t}^{w}\right)^{2}
$$

Wage inflation is given by

$$
\pi_{w, t}=\mu_{a c, t} \pi_{t} \frac{w_{t}}{w_{t-1}}
$$

We have some wage indexation to the previous period, and the aggregate wage index is given by

$$
\ddot{\pi}_{t}^{w} \equiv\left(\pi_{t-1}^{w}\right)^{\gamma_{w}}\left(\bar{\pi}^{w}\right)^{1-\gamma_{w}} .
$$

We have some price indexation to the previous period, and the aggregate price index is given by

$$
\ddot{\pi}_{t} \equiv \pi_{t-1}^{\gamma_{\pi}} \bar{\pi}^{1-\gamma_{\pi}}
$$

The production technology is given by

$$
y_{t}=\left(\frac{k_{t-1}}{\mu_{a c, t} \mu_{a i k, t}}\right)^{\alpha(1-\varrho)} o_{t}^{\alpha \varrho} n_{t}^{1-\alpha} .
$$

The neutral technology process is given by

$$
\mu_{a, t}=\exp \left(g_{a}+\sigma_{a} \epsilon_{a, t}\right)
$$

Firms select the quantity of labor, capital, and oil to maximize profits, which gives

$$
\begin{gathered}
p_{o, t}=\alpha \varrho \psi_{t} \frac{y_{t}}{o_{t}}, \\
r_{k, t}=\alpha(1-\varrho) \mu_{a c, t} \mu_{a i k, t} \psi_{t} \frac{y_{t}}{k_{t-1}}, \\
w_{t}=(1-\alpha) \psi_{t} \frac{y_{t}}{n_{t}} .
\end{gathered}
$$

Optimal price setting from the Rotemberg model:

$$
\begin{array}{r}
\frac{\epsilon}{\epsilon-1} \psi_{t}-\exp \left(\sigma_{\pi} \varepsilon_{\pi, t}\right)-\frac{\omega}{\epsilon-1} \pi_{t}\left(\pi_{t}-\ddot{\pi}_{t}\right) \\
+\mathbb{E}_{t}\left\{\frac{\omega}{\epsilon-1} m_{t}\left(\mu_{a c, t+1} \frac{y_{t+1}}{y_{t}}\right) \pi_{t+1}^{2}\left(\pi_{t+1}-\ddot{\pi}_{t+1}\right)\right\}=0 .
\end{array}
$$


The central bank follows a Taylor rule given by

$$
r_{t}=r_{t-1}^{\rho}\left(\bar{r}\left(\frac{y_{t}}{\bar{y}}\right)^{\kappa_{y}}\left(\frac{\pi_{t}}{\bar{\pi}}\right)^{\kappa_{\pi}}\right)^{1-\rho} \exp \left(\sigma_{r} \varepsilon_{r, t}\right) .
$$

Government spending follows an $\mathrm{AR}(1)$

$$
g=g_{t-1}^{\rho_{g}} \bar{g}^{1-\rho_{g}} \exp \left(\sigma_{g} \varepsilon_{g}\right)
$$

Government spending must be financed by taxes,

$$
g_{t}=\operatorname{tax}_{t}
$$

And aggregate debt is zero

$$
d_{t}=0
$$

Dividends or profits are given by

$$
d i v_{t}=y_{t}-w_{t} n_{t}-\frac{r_{k, t} k_{t-1}}{\mu_{a i k, t} \mu_{a c, t}}-p_{o, t} o_{t}+f_{t} .
$$

The growth rate of the consumption process is given by

$$
\mu_{a c, t}=\mu_{a, t}^{\frac{1}{1-\alpha}} \mu_{a i k, t}^{\frac{\alpha}{1-\alpha}} .
$$

Optimal wage setting a la Rotemberg

$$
\begin{aligned}
& \frac{v}{v-1} z_{t} \kappa_{t} \frac{n_{t}^{\vartheta}}{w_{t} \lambda_{t}}-1-\frac{\xi}{v-1} \pi_{t}^{w}\left(\pi_{t}^{w}-\ddot{\pi}_{t}^{w}\right) \\
& +\mathbb{E}_{t}\left\{\frac{\beta \lambda_{t+1}}{\lambda_{t} \pi_{t+1} \mu_{a c, t+1}} \frac{\xi}{v-1} \frac{n_{t+1}}{n_{t}}\left(\pi_{t+1}^{w}\right)^{2}\left(\pi_{t+1}^{w}-\ddot{\pi}_{t+1}^{w}\right)\right\}=0 .
\end{aligned}
$$

\section{B.2 Measurement equations}

The observed interest rate is equal to the interest rate in the model

$$
r_{o b s, t}=r_{t}
$$

The observed growth rate of world activity is equal to the growth rate of world activity in the model

$$
\Delta G D P_{o b s, t}^{W}=\Delta G D P_{t}^{W}
$$

The growth rate of output is defined as

$$
\Delta G D P_{t} \equiv \log \left(\mu_{a c, t}\right)+\log \left(\frac{y_{t}}{y_{t-1}}\right) .
$$

The growth rate of investment is defined as

$$
\Delta I N V_{t} \equiv \log \left(\mu_{a c, t}\right)+\log \left(\frac{i_{k, t}}{i_{k, t-1}}\right) .
$$


The growth rate of consumption spending is defined as,

$$
\triangle C O N S_{t} \equiv \log \left(\mu_{a c, t}\right)+\log \left(\frac{c_{t}}{c_{t-1}}\right)
$$

The growth rate of wages is defined as

$$
\triangle W A G E S_{t} \equiv \log \left(\pi_{t}^{w}\right)
$$

The growth rate of the consumer price index is defined as,

$$
\triangle C P I_{t} \equiv \log \left(\pi_{t}\right) .
$$

The growth rate of oil prices is defined as,

$$
\Delta P_{t}^{O i l} \equiv \log \left(\mu_{a i k, t}\right)+\log \left(\pi_{t}\right)+\log \left(\frac{p_{o, t}}{p_{o, t-1}}\right) .
$$

A description of all the endogenous, exogenous, and observable variables is given in the Tables 5, 3 and 4 respectively.

\section{B.3 The steady state}

The steady state of the system is given by the following relations

$$
\begin{aligned}
& n_{t}=\bar{n}, \quad z_{t}=1, \quad \mu_{a i k, t}=\exp \left(g_{a i k}\right), \quad q_{k, t}=1 \\
& \mu_{a, t}=\exp \left(g_{A}\right), \quad \pi_{t}=\bar{\pi}, \quad d_{t}=0, \quad g_{i k}=\log \left(\mu_{a c, t}\right) \\
& \mu_{a c, t}=\left(\mu_{a, t}\right)^{\frac{1}{1-\alpha}}\left(\mu_{a i k, t}\right)^{\frac{\alpha}{1-\alpha}}, \quad p_{o, t}=p_{o}, \quad r_{t}=\frac{1}{m_{t, t}} \\
& m_{t, t} \equiv \frac{\beta}{\mu_{a c, t} \pi_{t}}, \quad r_{k, t}=\left[\frac{\mu_{a c, t} \mu_{a i k, t}}{\beta}-1+\delta_{K}\right] q_{k, t} \\
& f_{t}=0, \quad \pi_{t}^{w} \equiv \mu_{a c, t} \pi_{t}, \quad \ddot{\pi}_{t}^{w} \equiv\left(\pi_{t}^{w}\right)^{\gamma_{w}}\left(\bar{\pi}^{w}\right)^{1-\gamma_{w}} \\
& \ddot{\pi}_{t} \equiv \pi_{t}^{\gamma_{\pi}} \bar{\pi}^{1-\gamma_{\pi}}, \quad \psi_{t}=\frac{\epsilon-1}{\epsilon}, \quad \frac{y}{k}=\frac{r_{k, t}}{\alpha(1-\varrho) \mu_{a c, t} \mu_{a i k, t} \psi_{t}} \\
& \frac{o}{k}=\frac{\alpha \varrho \psi_{t}}{p_{o, t}} \frac{y}{k}, \quad k_{t}=\frac{n_{t}}{\left[\left(\mu_{a c, t} \mu_{a i k, t}\right)^{(1-\varrho) \alpha}\left(\frac{o t}{k_{t}}\right)^{-\varrho \alpha} \frac{y_{t}}{k_{t}}\right]^{\frac{1}{1-\alpha}}} \\
& o_{t}=\left(\frac{o}{k}\right) k_{t}, \quad y_{t}=\left(\frac{y}{k}\right) k_{t}, \quad w_{t}=(1-\alpha) \frac{\psi_{t}}{n_{t}} y_{t} \\
& i_{k, t}=\left[1-\frac{\left(1-\delta_{K}\right)}{\mu_{a c, t} \mu_{a i k, t}}\right] k_{t}, \quad g_{t}=\left(\frac{G}{Y}\right) y_{t}, \quad \operatorname{tax}_{t}=g_{t} \\
& c_{t}=y_{t}-\operatorname{tax}_{t}-\left(\frac{r_{t}}{\mu_{a c, t} \pi_{t}}-1\right) d_{t}-i_{k, t} \text {, with } c_{t}>0 \\
& \lambda_{t}=z_{t}\left(c_{t}-\chi \frac{c_{t}}{\mu_{a c, t}}\right)^{-\sigma}, \quad d i v_{t}=y_{t}-w_{t} n_{t}-\frac{1}{\mu_{a i k, t} \mu_{a c, t}} r_{k, t} k_{t}+f_{t} \\
& \kappa_{t}=\frac{(v-1) w_{t} \lambda_{t}}{v, \quad \kappa=\kappa_{t} z_{t} n_{t}^{\vartheta}}
\end{aligned}
$$




\section{B.4 Description of the variables}

In this section we list the variables in our model together with a short description. Table 3 lists the exogenous variables, Table 4 lists the observable variables and Table 5 lists the endogenous variables.

Table 3: Exogenous variables

\begin{tabular}{lr}
\hline Variable & Description \\
\hline$\varepsilon_{A}$ & Neutral technology shock \\
$\varepsilon_{A I K}$ & Investment specific technology shock \\
$\varepsilon_{G}$ & Government spending shock \\
$\varepsilon_{\kappa}$ & Labor preference shock \\
$\varepsilon_{o}$ & Oil price shock \\
$\varepsilon_{W}$ & World oil demand shock \\
$\varepsilon_{\pi}$ & Stochastic subsidy shock \\
$\varepsilon_{r}$ & Monetary policy shock \\
$\varepsilon_{z}$ & Consumption preference shock \\
\hline
\end{tabular}

Table 4: Observable variables

\begin{tabular}{lr}
\hline Variable & Description \\
\hline$\triangle C O N S$ & Consumption growth \\
$\Delta C P I$ & CPI inflation \\
$\Delta G D P$ & GDP growth \\
$\Delta I N V$ & Investment growth \\
$\Delta P^{\text {Oil }}$ & Oil price inflation \\
$\Delta W A G E S$ & Wage inflation \\
$\Delta G D P^{W}$ & World GDP growth \\
$r$ & Interest rate \\
\hline
\end{tabular}


Table 5: Endogenous variables

\begin{tabular}{|c|c|}
\hline Variable & Description \\
\hline$c$ & Aggregate consumption \\
\hline$d$ & Deposits/Loans \\
\hline$\triangle C O N S$ & Consumption growth \\
\hline$\triangle C P I$ & CPI inflation \\
\hline$\triangle G D P$ & GDP growth \\
\hline$\triangle G O V$ & Government spending growth \\
\hline$\triangle I N V$ & Investment growth \\
\hline div & Dividends \\
\hline$\Delta P^{O i l}$ & Oil price inflation \\
\hline$\triangle W A G E S$ & Wage inflation \\
\hline$f$ & Membership fees \\
\hline$g$ & Government spending \\
\hline$i_{k}$ & Investment \\
\hline$k$ & Capital \\
\hline$\kappa$ & Labor preferences \\
\hline$\lambda$ & Marginal utility of consumption \\
\hline$p_{\mathrm{o}}$ & Real oil price \\
\hline$m$ & Stochastic discount factor \\
\hline$\mu_{a}$ & Neutral technology process \\
\hline$\mu_{a i k}$ & Capital investment shock process \\
\hline$n$ & Labor \\
\hline$O$ & Oil demand \\
\hline$\Delta G D P^{W}$ & World GDP growth \\
\hline$\pi$ & Inflation \\
\hline$\ddot{\pi}$ & Inflation index \\
\hline$\pi_{w}$ & Wage inflation \\
\hline$\ddot{\pi}^{w}$ & Wage inflation index \\
\hline$p_{o}$ & Price of oil \\
\hline$\psi$ & Real marginal cost \\
\hline$q_{k}$ & Price of capital goods \\
\hline$r$ & Interest rate \\
\hline$r_{k}$ & Rental rate of capital \\
\hline $\operatorname{tax}$ & Taxes \\
\hline$w$ & Wages \\
\hline$y$ & Output \\
\hline$z$ & Intertemporal preference shifter \\
\hline
\end{tabular}




\section{A model for oil and the rest of the world}

We model growth in world activity and the real oil price jointly in a bi-variate VAR model given by

$$
\boldsymbol{A}_{0}\left[\begin{array}{c}
\Delta \log \left(G D P_{t}^{\mathrm{W}}\right) \\
\log \left(p_{o, t}\right)
\end{array}\right]=\boldsymbol{c}+\sum_{j=1}^{2} \boldsymbol{A}_{j}\left[\begin{array}{c}
\Delta \log \left(G D P_{t-j}^{\mathrm{W}}\right) \\
\log \left(p_{o, t-j}\right)
\end{array}\right]+\left[\begin{array}{c}
\sigma_{t}^{\mathrm{W}} \varepsilon_{W, t} \\
\sigma_{t}^{\text {Oil }}\left(\mathcal{S}_{t}^{\mathrm{Oil}}\right) \varepsilon_{o, t}
\end{array}\right]
$$

where the $\boldsymbol{A}$ matrices are given by

$$
\boldsymbol{A}_{0} \equiv\left[\begin{array}{cc}
1 & 0 \\
a_{0,21} & 1
\end{array}\right], \boldsymbol{A}_{1} \equiv\left[\begin{array}{cc}
a_{1,11} & a_{1,12} \\
a_{1,21} & a_{1,22}
\end{array}\right] \text { and } \boldsymbol{A}_{2} \equiv\left[\begin{array}{cc}
a_{2,11} & a_{2,12} \\
a_{2,21} & a_{2,22}
\end{array}\right]
$$

The impulse responses from the oil - macroeconomic relationship is given in the paper, Table 6 displays the priors and the posterior (modes and medians) for the VAR parameters.

Table 6: Priors and posteriors

\begin{tabular}{lrrrrrrrr}
\hline & \multicolumn{3}{c}{ Prior } & & \multicolumn{4}{c}{ Posterior } \\
\cline { 2 - 3 } \cline { 8 - 10 } Param. & Distr. & $5 \%$ & $95 \%$ & & Mode & Median & $5 \%$ & $95 \%$ \\
\hline$a_{1,11}$ & Normal & -1.158 & 2.132 & & 0.5833 & 0.5283 & 0.3927 & 0.6726 \\
$a_{1,12}$ & Normal & -1.644 & 1.646 & & 0.0019 & 0.0018 & -0.0038 & 0.0075 \\
$a_{2,11}$ & Normal & -1.603 & 1.686 & & -0.0027 & 0.0558 & -0.0521 & 0.1276 \\
$a_{2,12}$ & Normal & -1.648 & 1.642 & & -0.0030 & -0.0030 & -0.0069 & 0.0007 \\
$a_{0,21}$ & Normal & -2.079 & 1.211 & & -0.3821 & -0.4768 & -0.7721 & -0.2215 \\
$a_{1,21}$ & Normal & 1.352 & 4.642 & & 3.073 & 3.017 & 2.882 & 3.1 \\
$a_{1,22}$ & Normal & -0.4902 & 2.799 & & 1.295 & 1.235 & 1.167 & 1.321 \\
$a_{2,21}$ & Normal & -4.946 & -1.656 & & -2.938 & -3.173 & -3.417 & -2.923 \\
$a_{2,22}$ & Normal & -1.832 & 1.458 & & -0.3083 & -0.2473 & -0.3353 & -0.1756 \\
\hline
\end{tabular}




\section{Specification of the different regimes}

In our model set-up we specify two monetary policy states (hawkish and dovish), two macro volatility states (high and low) and two oil price volatility states (high and low). Combining these states gives us eight possible regimes, see Table 7 for a specification of the different regimes by combining of different states.

Table 7: Specification of the regimes

\begin{tabular}{lccc}
\hline & Macroeconomic volatility & Oil price volatility & Monetary policy \\
\hline Regime 1 $\left(\mathcal{S}_{t}=1\right)$ & $\mathcal{S}_{t}^{\text {Vol }}=$ High & $\mathcal{S}_{t}^{\text {Oil }}=$ High & $\mathcal{S}_{t}^{\text {Pol }}=$ Hawkish \\
Regime 2 $\left(\mathcal{S}_{t}=2\right)$ & $\mathcal{S}_{t}^{\text {Vol }}=$ High & $\mathcal{S}_{t}^{\text {Oil }}=$ High & $\mathcal{S}_{t}^{\text {Pol }}=$ Dovish \\
Regime 3 $\left(\mathcal{S}_{t}=3\right)$ & $\mathcal{S}_{t}^{\text {Vol }}=$ High & $\mathcal{S}_{t}^{\text {Oil }}=$ Low & $\mathcal{S}_{t}^{\text {Pol }}=$ Hawkish \\
Regime 4 $\left(\mathcal{S}_{t}=4\right)$ & $\mathcal{S}_{t}^{\text {Vol }}=$ High & $\mathcal{S}_{t}^{\text {Oil }}=$ Low & $\mathcal{S}_{t}^{\text {Pol }}=$ Dovish \\
Regime 5 $\left(\mathcal{S}_{t}=5\right)$ & $\mathcal{S}_{t}^{\text {Vol }}=$ Low & $\mathcal{S}_{t}^{\text {Oil }}=$ High & $\mathcal{S}_{t}^{\text {Pol }}=$ Hawkish \\
Regime 6 $\left(\mathcal{S}_{t}=6\right)$ & $\mathcal{S}_{t}^{\text {Vol }}=$ Low & $\mathcal{S}_{t}^{\text {Oil }}=$ High & $\mathcal{S}_{t}^{\text {Pol }}=$ Dovish \\
Regime 7 $\left(\mathcal{S}_{t}=7\right)$ & $\mathcal{S}_{t}^{\text {Vol }}=$ Low & $\mathcal{S}_{t}^{\text {Oil }}=$ Low & $\mathcal{S}_{t}^{\text {Pol }}=$ Hawkish \\
Regime 8 $\left(\mathcal{S}_{t}=8\right)$ & $\mathcal{S}_{t}^{\text {Vol }}=$ Low & $\mathcal{S}_{t}^{\text {Oil }}=$ Low & $\mathcal{S}_{t}^{\text {Pol }}=$ Dovish \\
\hline
\end{tabular}




\section{E Additional Results}

Table 8 - 15 reports the variance decomposition for an oil price shock in the eight different regimes. Figure $7-14$ displays the smoothed probabilities for being in the different regimes.

Table 15 investigates the robustness of starting the estimation period in 1975Q1 while Table 16 investigates the robustness of ending the estimation period in 2008Q4.

Table 8: Variance decomposition regime 1

\begin{tabular}{cccccccc}
\hline & 1 & 4 & 8 & 12 & 16 & 20 & 40 \\
\hline GDP growth & 0.21 & 2.30 & 3.80 & 3.90 & 3.90 & 3.90 & 4.00 \\
Price Inflation & 37.00 & 35.00 & 32.00 & 33.00 & 34.00 & 36.00 & 42.00 \\
Wage inflation & 12.00 & 9.10 & 8.40 & 8.90 & 10.00 & 11.00 & 17.00 \\
Interest Rate & 10.00 & 29.00 & 33.00 & 34.00 & 35.00 & 38.00 & 48.00
\end{tabular}

Note: Regime 1: High macro vol \& High oil price vol \& Hawkish state. Variance Decomposition: Contribution of Oil shocks.

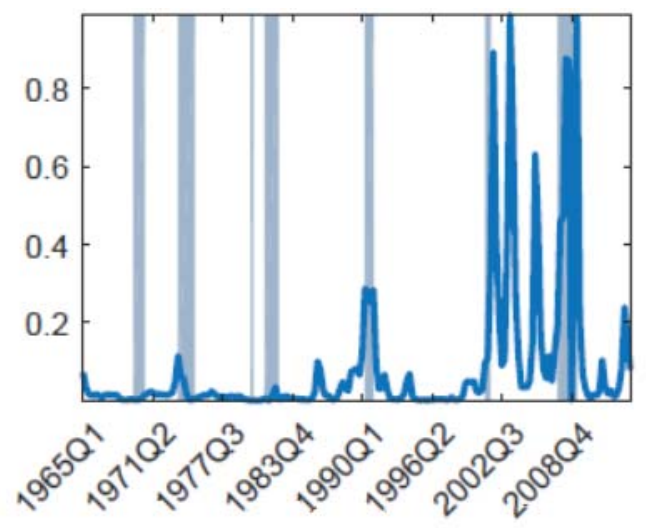

Figure 7: Smoothed probabilities for regime 1 
Table 9: Variance decomposition regime 2

\begin{tabular}{cccccccc}
\hline & 1 & 4 & 8 & 12 & 16 & 20 & 40 \\
\hline GDP growth & 4.30 & 4.40 & 4.30 & 4.40 & 4.40 & 4.40 & 4.50 \\
Price Inflation & 45.00 & 42.00 & 42.00 & 43.00 & 45.00 & 47.00 & 52.00 \\
Wage inflation & 29.00 & 29.00 & 31.00 & 33.00 & 35.00 & 36.00 & 41.00 \\
Interest Rate & 13.00 & 35.00 & 39.00 & 41.00 & 43.00 & 45.00 & 52.00 \\
\hline
\end{tabular}

Note: Regime 2: High macro vol \& High oil price vol \& Dovish state.

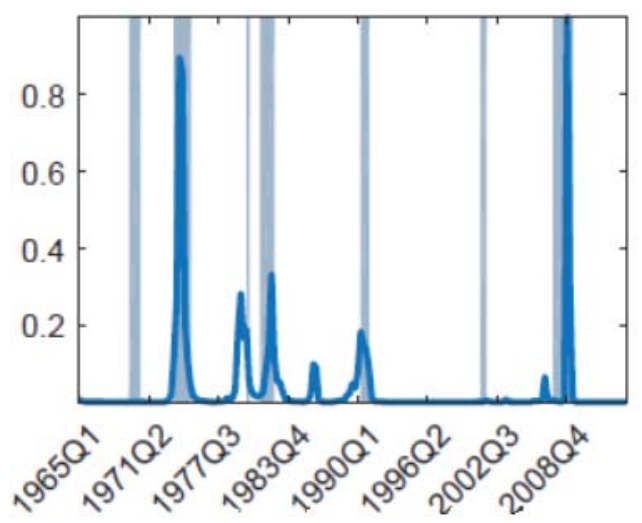

Figure 8: Smoothed probabilities for regime 2 
Table 10: Variance decomposition regime 3

\begin{tabular}{cccccccc}
\hline & 1 & 4 & 8 & 12 & 16 & 20 & 40 \\
\hline GDP growth & 0.01 & 0.18 & 0.30 & 0.31 & 0.31 & 0.31 & 0.31 \\
Price Inflation & 4.20 & 3.90 & 3.50 & 3.50 & 3.80 & 4.00 & 5.10 \\
Wage inflation & 0.99 & 0.76 & 0.69 & 0.73 & 0.83 & 0.96 & 1.60 \\
Interest Rate & 0.86 & 3.00 & 3.60 & 3.70 & 4.00 & 4.30 & 6.60 \\
\hline
\end{tabular}

Note: Regime 3: High macro vol \& Low oil price vol \& Hawkish state.

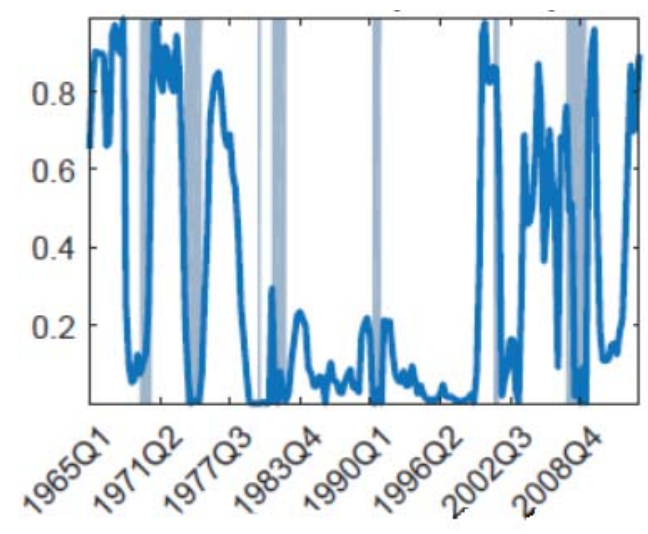

Figure 9: Smoothed probabilities for regime 3 
Table 11: Variance decomposition regime 4

\begin{tabular}{cccccccc}
\hline & 1 & 4 & 8 & 12 & 16 & 20 & 40 \\
\hline GDP growth & 0.34 & 0.34 & 0.34 & 0.34 & 0.35 & 0.35 & 0.35 \\
Price Inflation & 5.80 & 5.30 & 5.10 & 5.40 & 5.80 & 6.20 & 7.50 \\
Wage inflation & 3.00 & 3.00 & 3.20 & 3.50 & 3.80 & 4.10 & 5.00 \\
Interest Rate & 1.10 & 3.80 & 4.60 & 4.90 & 5.40 & 5.90 & 7.50 \\
\hline
\end{tabular}

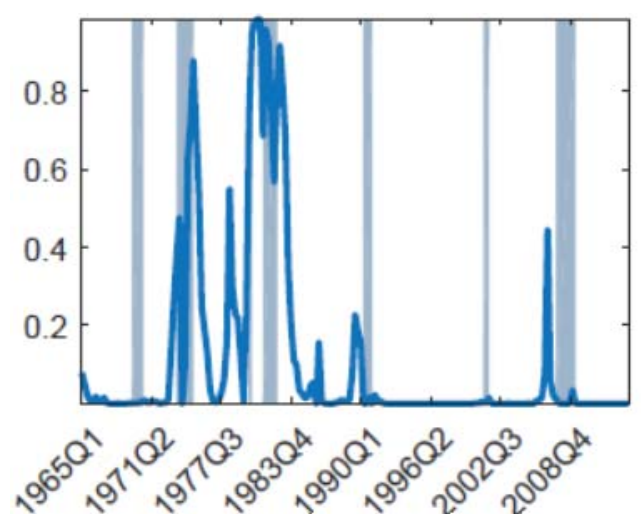

Figure 10: Smoothed probabilities for regime 4 
Table 12: Variance decomposition regime 5

\begin{tabular}{cccccccc}
\hline & 1 & 4 & 8 & 12 & 16 & 20 & 40 \\
\hline GDP growth & 0.82 & 8.50 & 13.00 & 14.00 & 14.00 & 14.00 & 14.00 \\
Price Inflation & 68.00 & 65.00 & 63.00 & 64.00 & 66.00 & 67.00 & 73.00 \\
Wage inflation & 31.00 & 27.00 & 26.00 & 27.00 & 30.00 & 33.00 & 45.00 \\
Interest Rate & 12.00 & 45.00 & 61.00 & 65.00 & 67.00 & 70.00 & 79.00 \\
\hline
\end{tabular}

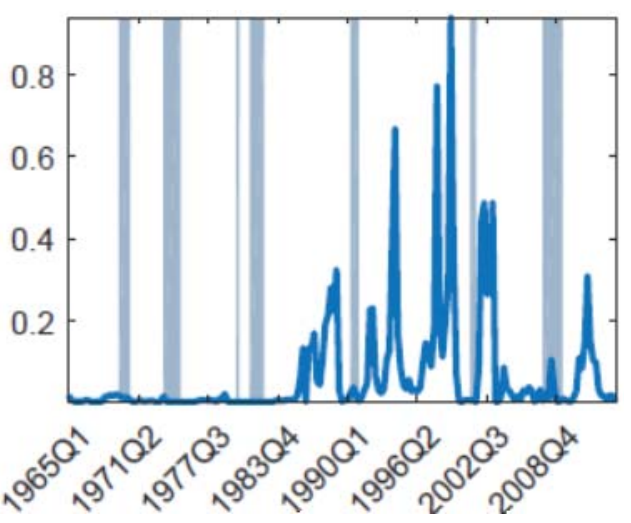

Figure 11: Smoothed probabilities for regime 5 
Table 13: Variance decomposition regime 6

\begin{tabular}{cccccccc}
\hline & 1 & 4 & 8 & 12 & 16 & 20 & 40 \\
\hline GDP growth & 16.00 & 17.00 & 16.00 & 17.00 & 17.00 & 17.00 & 17.00 \\
Price Inflation & 79.00 & 78.00 & 78.00 & 78.00 & 80.00 & 81.00 & 84.00 \\
Wage inflation & 65.00 & 66.00 & 67.00 & 69.00 & 71.00 & 73.00 & 77.00 \\
Interest Rate & 15.00 & 54.00 & 67.00 & 71.00 & 74.00 & 76.00 & 80.00 \\
\hline
\end{tabular}

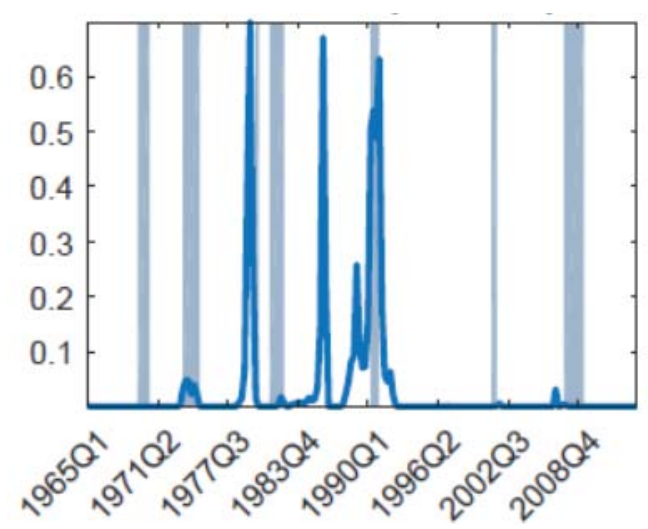

Figure 12: Smoothed probabilities for regime 6 
Table 14: Variance decomposition regime 7

\begin{tabular}{cccccccc}
\hline & 1 & 4 & 8 & 12 & 16 & 20 & 40 \\
\hline GDP growth & 0.06 & 0.70 & 1.20 & 1.20 & 1.20 & 1.20 & 1.20 \\
Price Inflation & 14.00 & 12.00 & 12.00 & 12.00 & 13.00 & 13.00 & 17.00 \\
Wage inflation & 3.30 & 2.70 & 2.50 & 2.70 & 3.10 & 3.60 & 5.80 \\
Interest Rate & 1.00 & 5.90 & 10.00 & 12.00 & 14.00 & 15.00 & 22.00 \\
\hline Note: Regime 7: Low
\end{tabular}

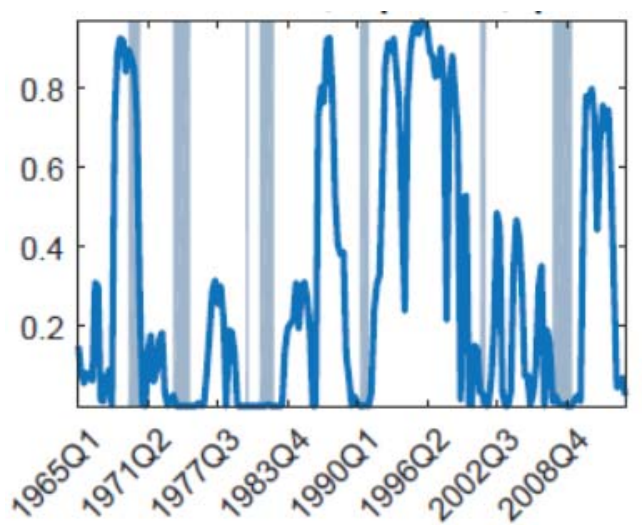

Figure 13: Smoothed probabilities for regime 7 
Table 15: Variance decomposition regime 8

\begin{tabular}{cccccccc}
\hline & 1 & 4 & 8 & 12 & 16 & 20 & 40 \\
\hline GDP growth & 1.50 & 1.50 & 1.50 & 1.50 & 1.50 & 1.50 & 1.50 \\
Price Inflation & 22.00 & 21.00 & 21.00 & 22.00 & 23.00 & 24.00 & 28.00 \\
Wage inflation & 12.00 & 13.00 & 13.00 & 15.00 & 16.00 & 17.00 & 20.00 \\
Interest Rate & 1.30 & 8.00 & 13.00 & 16.00 & 17.00 & 19.00 & 23.00 \\
\hline
\end{tabular}

Note: Regime 8: Low macro vol \& Low oil price vol \& Dovish state.

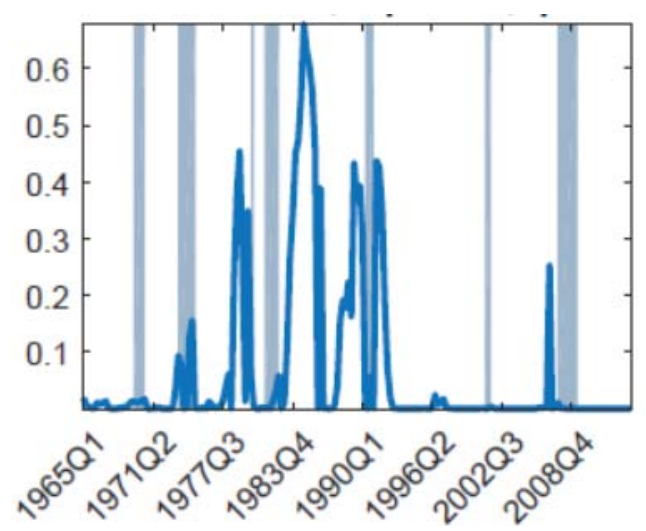

Figure 14: Smoothed probabilities for regime 8 

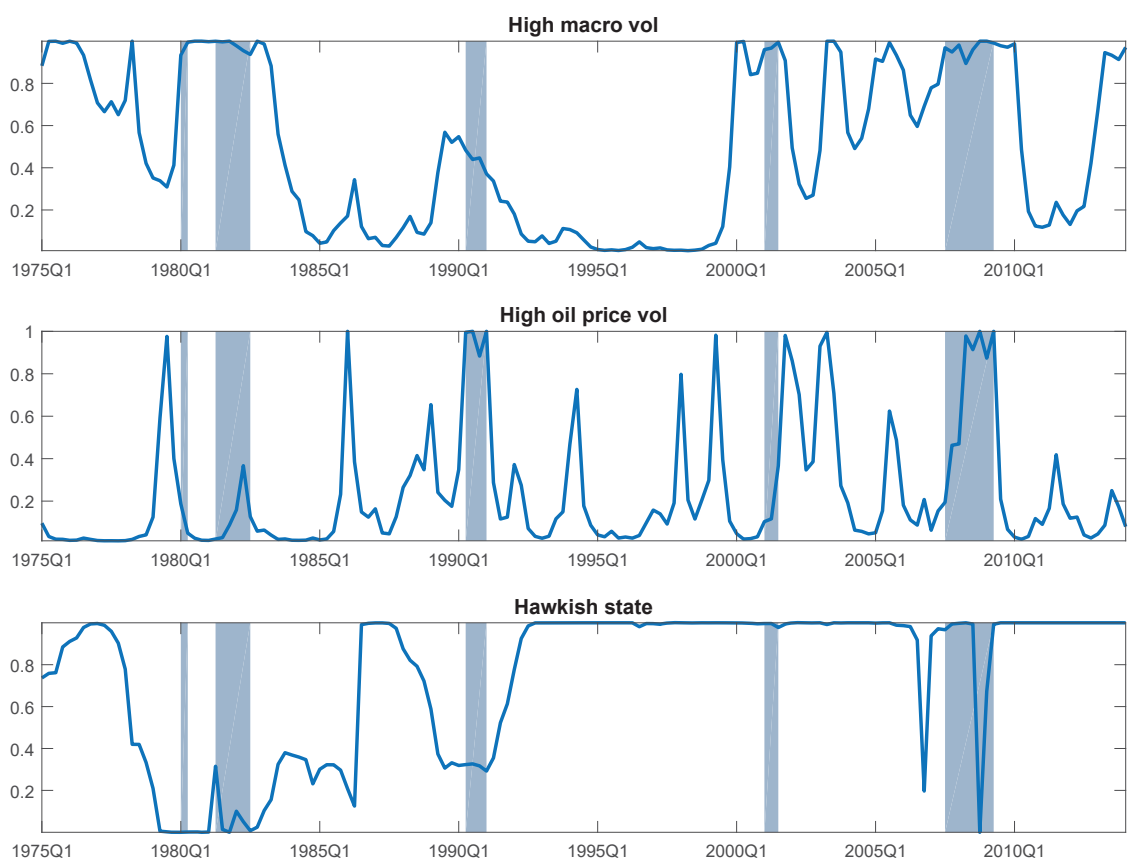

Figure 15: Smoothed state probabilities (starting in 1975Q1)

Note: The top row presents the smoothed probabilities for being in the high macroeconomic volatility regime. The second row presents the smoothed probabilities for being in the high oil price volatility regime. The bottom row presents the smoothed probabilities for being in the high monetary policy response regime. 

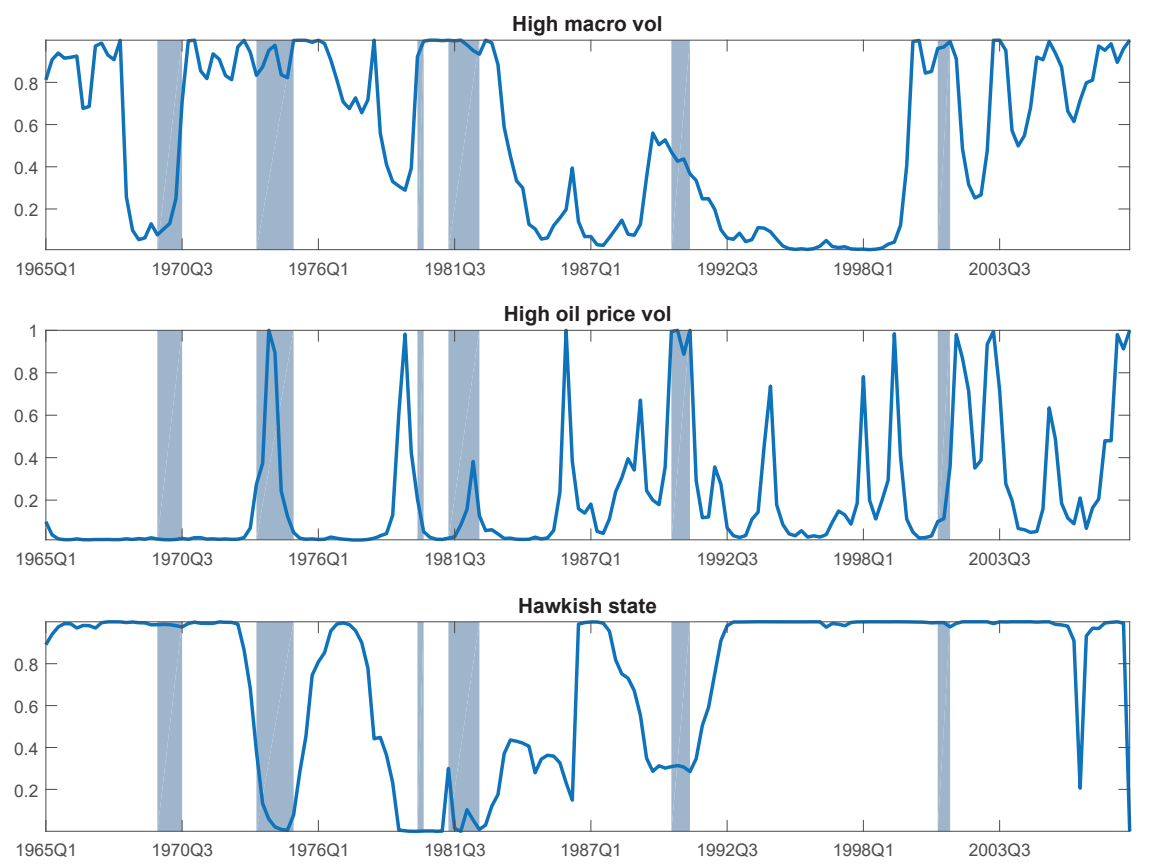

Figure 16: Smoothed state probabilities (ending in 2008Q4)

Note: The top row presents the smoothed probabilities for being in the high macroeconomic volatility regime. The second row presents the smoothed probabilities for being in the high oil price volatility regime. The bottom row presents the smoothed probabilities for being in the high monetary policy response regime. 